\title{
Phylogenetic placement of Leptosphaeria polylepidis, a pathogen of Andean endemic Polylepis tarapacana, and its newly discovered mycoparasite Sajamaea mycophila gen. et sp. nov.
}

\author{
Marcin Piątek $^{1}$ (D) Pamela Rodriguez-Flakus ${ }^{2}$ (D) Alejandra Domic $^{3,4}\left(\mathbb{D} \cdot\right.$ Arely N. Palabral-Aguilera $^{5} \cdot$ \\ M. Isabel Gómez ${ }^{6}$ (D) Adam Flakus $^{7}$ (i)
}

Received: 12 April 2019 / Revised: 15 October 2019 / Accepted: 21 October 2019

(C) The Author(s) 2019

\begin{abstract}
Polylepis tarapacana forms one of the highest-altitude woodlands worldwide. Its populations are experiencing a decline due to unsustainable land-use practices, climate change, and fungal infection. In Sajama National Park in Bolivia, Polylepis tarapacana is affected by a disease caused by the pleosporalean fungus Leptosphaeria polylepidis, recently described in 2005. In this study, the integrative morphological and molecular analyses using sequences from multiple DNA loci showed that it belongs to the genus Paraleptosphaeria (Leptosphaeriaceae, Pleosporales). Accordingly, the appropriate new combination, Paraleptosphaeria polylepidis, is made. Pseudothecia of Pa. polylepidis were found to be overgrown by enigmatic conidiomata that were not reported in the original description of this fungus. Morphological and molecular analyses using sequences from two DNA loci revealed that they belong to an undescribed genus and species in the family Dictyosporiaceae (Pleosporales). The new generic and specific names, Sajamaea and S. mycophila, are introduced for this unusual fungus.
\end{abstract}

Keywords Andes $\cdot$ Mycoparasite $\cdot$ New genus $\cdot$ New species $\cdot$ Pleosporales $\cdot$ Plant pathogen $\cdot$ Polylepis $\cdot$ South America

\section{Introduction}

Along the Andes, dispersed woodlands of Polylepis (Rosaceae) constitute a common component of the treeline. Polylepis woodlands are characterized by being dominated either mostly or exclusively by representatives of this genus and by being found in areas of difficult access, including rocky outcrops and mountain slopes (Fjeldså and Kessler 1996; Kessler 2006). These woodlands are important habitats for plant and animal species, including several endangered

Section Editor: Hans-Josef Schroers

Marcin Piątek

m.piatek@botany.pl

Pamela Rodriguez-Flakus

p.rodriguez@botany.pl

1 Department of Mycology, W. Szafer Institute of Botany, Polish Academy of Sciences, Lubicz 46, 31-512 Kraków, Poland

2 Department of Vascular Plants, W. Szafer Institute of Botany, Polish Academy of Sciences, Lubicz 46, 31-512 Kraków, Poland habitat-specialist bird species (Fjeldså and Kessler 1996) and constitute important sources of firewood, fodder, and medicinal plants for local indigenous communities (Fjeldså and Kessler 1996; Domic et al. 2014; Hurtado et al. 2018). Polylepis woodlands are experiencing a rapid decline due to unsuitable land use practices, habitat destruction, and ongoing climate change (Navarro et al. 2005).

Polylepis tarapacana is a species that includes small trees and shrubs distributed along the semiarid Andean highlands from Peru to Argentina and Chile (Kessler 1995). The species

Department of Anthropology, The Pennsylvania State University, University Park, PA 16802, USA

4 Department of Geosciences, The Pennsylvania State University, University Park, PA 16802, USA

5 Instituto de Ecología, Herbario Nacional de Bolivia, Calle 27 Cota Cota, La Paz, Bolivia

6 Colección Boliviana de Fauna, Museo Nacional de Historia Natural, La Paz, Bolivia

Department of Lichenology, W. Szafer Institute of Botany, Polish Academy of Sciences, Lubicz 46, 31-512 Kraków, Poland 
possess morphological (Simpson 1979; Kessler 1995) and physiological adaptations (Rada et al. 2001; Azócar et al. 2007; González et al. 2007) to tolerate frost and desiccation due to extreme environmental conditions, including high solar irradiance, night frosts, and high diurnal temperature variation. In Nevado Sajama in Bolivia, P. tarapacana forms one of the world's highest-altitude woodlands, reaching elevations up to $5200 \mathrm{~m}$ a.s.1. (Jordan 1980). The species is currently categorized as "Vulnerable" in Bolivia due to firewood extraction, habitat loss, and climate change (MMAyA 2012; Cuyckens et al. 2016). A potentially pathogenic fungus, Leptosphaeria polylepidis, constitutes an emerging threat to the permanence of remaining $P$. tarapacana woodlands, as its infection has been attributed to the mortality of several individuals in the Sajama National Park (Coca-Morante 2012). The fungus, originally described from two collections made in 2002 in the Sajama National Park, forms stromatic black knots on the branches of infected individuals of $P$. tarapacana (Macía et al. 2005). Recent evaluations have shown that the infection is widespread in protected areas particularly of the southeast and northeast slopes of Nevado Sajama. However, actions to control the spread of the infection have not been implemented due to a lack of knowledge regarding the lifecycle and pathogenicity of $L$. polylepidis.

The genus Leptosphaeria, with the type species Leptosphaeria doliolum, resides in the Leptosphaeriaceae within Pleosporales (Zhang et al. 2012; de Gruyter et al. 2013; Ariyawansa et al. 2015). It contains hundreds of described species that in recent molecular analyses were proven to belong to different genera, including Brunneosphaerella, Heterospora, Neoleptosphaeria, Paraleptosphaeria, Plenodomus, Pseudoleptosphaeria, or Subplenodomus (Crous et al. 2009; de Gruyter et al. 2013; Ariyawansa et al. 2015). The generic placement of the majority of Leptosphaeria species is, however, still uncertain, and their rearrangements into the correct genus need molecular phylogenetic analyses, ideally using freshly collected materials. When describing Leptosphaeria polylepidis, Macía et al. (2005) provided a nuc rDNA ITS1-5.8S-ITS2 (ITS) sequence from the holotype material. Comparing this sequence with sequences available at that time in GenBank, they found that L. polylepidis was most similar to Leptosphaeria dryadis, a parasite of Dryas octopetala in arctic and alpine regions of the Northern Hemisphere. Leptosphaeria dryadis is currently placed in the genus Paraleptosphaeria (de Gruyter et al. 2013). However, it is not clear if this is also the correct genus for L. polylepidis because the ITS sequence generated by Macía et al. (2005) was not included in any of the subsequent studies dealing with Leptosphaeria-like species; many new sequences of Leptosphaeria-like species were generated in recent years that could disprove close relationships between L. polylepidis and Paraleptosphaeria dryadis, and sequences from more than one DNA locus can better resolve generic boundaries within Leptosphaeriaceae (Ariyawansa et al. 2015).

Therefore, it is the aim of this study to resolve the phylogenetic and generic placement of Leptosphaeria polylepidis by employing integrative morphological and molecular analyses using sequences from multiple DNA loci. During the analyses of freshly collected material, we unexpectedly found that pseudothecia of L. polylepidis were overgrown by conidiomata that were not reported in the original description of the fungus. It was not clear if these conidiomata represented an asexual state of L. polylepidis or, alternatively, belonged to a mycoparasitic fungus. Therefore, the second aim of this study was to answer this question by applying morphological and molecular analyses using nuc rDNA ITS and LSU sequences.

\section{Materials and methods}

\section{Specimen sampling and documentation}

This study is based on newly collected material of Leptosphaeria polylepidis. Four specimens were collected in the Sajama National Park in Bolivia, which is the type locality and the only known place of occurrence of L. polylepidis. One of them was partly covered with conidiomata. This specimen was used for detailed morphological/anatomical and molecular analyses. The voucher material is preserved at the Herbario Nacional de Bolivia (LPB) and at the fungal herbarium of the W. Szafer Institute of Botany, Polish Academy of Sciences, Kraków (KRAM F). Attempts to obtain cultures failed.

\section{Morphological analyses}

The morphology was examined using standard stereo and light microscopy (Nikon SMZ 800, Nikon Eclipse 80i DIC). Thin sections of ascomata and conidiomata were made manually using a razor blade or with the aid of a freezing microtome Thermo Scientific Microm HM430 equipped with BFSMP freezing stage and BFS-3MP controller. The sectioned material was examined in distilled water, $10 \%$ solution of potassium hydroxide $(\mathrm{KOH})$, or lactophenol cotton blue (LPCB). The amyloidity of fungal structures was tested using Lugol's solution (IKI), or a combination of first $\mathrm{KOH}$ and then IKI (KOH/IKI). All measurements were made in distilled water.

\section{DNA isolation, PCR, and sequencing}

Genomic DNA was extracted in three separate extraction rounds, namely one extraction from 10 pseudothecial hymenia of Leptosphaeria polylepidis, one extraction from conidial mass obtained from five conidiomata, and one extraction from 15 entire conidiomata of unknown fungus, using the 
DNeasy ${ }^{\mathrm{TM}}$ Plant Mini Kit or QIAamp DNA Investigator Kit (Qiagen, Germany), following the manufacturer's instructions. For Leptosphaeria polylepidis, a total of four genetic markers were amplified, namely nuc rDNA $18 \mathrm{~S}$ (SSU), nuc rDNA ITS1-5.8S-ITS2 (ITS), nuc rDNA 28S (LSU), and a fragment of the translation elongation factor 1-alpha gene (TEF1). For unknown conidiomatal fungus, two genetic markers were amplified, namely ITS and LSU. The following primer pairs were used for amplification: NS1-NS24 (White et al. 1990; Gargas and Taylor 1992), ITS1F-ITS4 (White et al. 1990; Gardes and Bruns 1993), LROR-LR7 (Vilgalys and Hester 1990; Rehner and Samuels 1994), and EF1983FEF12218R (Rehner and Buckley 2005) for SSU, ITS, LSU, and TEF1, respectively. Polymerase chain reactions (PCRs) were performed as follows: for Leptosphaeria polylepidis, $2 \mu \mathrm{l}$ of DNA extract was used for SSU, ITS, and LSU and $5 \mu \mathrm{l}$ for $T E F 1$, while for unknown conidiomatal fungus, $3 \mu \mathrm{l}$ of DNA extract was used for ITS and LSU in a total volume of $25 \mu \mathrm{l}$ PCR reactions; the rest of components were added according to Flakus et al. (2019). Cycling conditions were performed as reported by Rodriguez-Flakus and Printzen (2014) for the nuclear markers and Rehner and Buckley (2005) for $T E F 1$ with modification of the initial denaturalization to $4 \mathrm{~min}$ and final extension to $5 \mathrm{~min}$ (M. Mardones, pers. comm.). PCR products were visualized on agarose gels and later purified using ExoSap. The PCR amplicons were sequenced by Macrogen Europe B.V. (Amsterdam, the Netherlands).

\section{Phylogenetic analyses}

Newly generated sequences were trimmed, assembled, and edited using Geneious Pro, version 8.0.5 (Biomatters Inc.). BLAST searches in GenBank (Altschul et al. 1997) were performed to find sequences of most closely related species, revealing affinities of sequences from Leptosphaeria polylepidis to sequences of the Leptosphaeriaceae and sequences obtained from unknown conidiomatal fungus to sequences of the Dictyosporiaceae. Accordingly, two separate datasets were assembled to resolve the phylogenetic placement of each fungus.

To resolve the phylogenetic position of Leptosphaeria polylepidis, a four-gene dataset (SSU+ITS+LSU+TEF1) was assembled that included sequences generated in this study and sequences from 45 specimens of closely related members of the Leptosphaeriaceae and a member of the Cucurbitariaceae used as an outgroup (selected from Zhang et al. 2012 and Tibpromma et al. 2017; see Table 1). Each single gene dataset was aligned separately using the MAFFT algorithm (Katoh et al. 2005) as implemented on the GUIDANCE web-server (Penn et al. 2010); to remove poorly or ambiguously aligned uncertain columns, a default cut-off score of 0.93 in all single gene alignments were chosen. The single-gene datasets were concatenated to a final alignment using Geneious Pro and consisted of 1023 bp (SSU), 452 bp (ITS), 1326 bp (LSU), and 915 bp (TEF1). Subsequently, the analyses were performed in the CIPRES Scientific gateway portal (:dito existshttp://www.phylo.org/portal2) (Miller et al. 2010). The optimal partitioning scheme and substitution models for each single-gene alignment were inferred by PartitionFinder 2 (Lanfear et al. 2016). A single partition for SSU and LSU; three partitions for ITS1, 5.8S, and ITS2 regions; and three for each of the codon positions of TEF1 were found. Substitution models selected under the greedy search algorithm and Akaike information criterion (Lanfear et al. 2016) were TVM+G+I for SSU, ITS2, and LSU; JC+I for 5.8S; and $\mathrm{GTR}+\mathrm{G}$ for ITS1 and used as priors for Bayesian phylogenetic inference (BI) analyses. Maximum likelihood (ML) and bootstrap support (BS) analyses were performed on each locus separately and concatenated data set by using RAxML-HPC2 on XSEDE with a rapid BS algorithm (Stamatakis 2014), 1000 replicates, and GTRGAMMA substitution model. Bayesian inference (BI) analyses were carried out using Markov Chain Monte Carlo as implemented in MrBayes on XSEDE (Huelsenbeck and Ronquist 2001; Ronquist and Huelsenbeck 2003) and were based on 10 million generations, sampling every 1000th tree, two independent parallel runs of four incrementally heated chains $(0.15)$ and discarding the first 0.5 of the sampled trees.

To resolve phylogenetic position of the conidiomatal fungus, a two-gene dataset (ITS+LSU) was assembled, which contained sequences generated in this study and sequences from 28 related members of the Dictyosporiaceae and two sequences of Periconia igniaria used as an outgroup (selected from Iturrieta-González et al. 2018 and Yang et al. 2018; see Table 2). Phylogenetic analyses were performed as described above and were based on 820 bp (LSU) and 412 bp (ITS) alignments. A single partition for $\mathrm{LSU}(\mathrm{GTR}+\mathrm{I}+\mathrm{G})$ and three partitions for ITS $(\mathrm{GTR}+\mathrm{G}$ for ITS1, SYM $+\mathrm{I}+\mathrm{G}$ for $5.8 \mathrm{~S}$, and JC+I+G for ITS2) were selected based on PartitionFinder 2 (Lanfear et al. 2016). The ML and BI analyses were performed with similar parameters as described above, but 20 million generations in four independent parallel runs were sampled and six gradually heated chains used. Relationships receiving bootstrap support (ML-BP) above $70 \%$ and 0.95 as Bayesian posterior probability (PP) were considered strongly supported. The resulting trees from both phylogenetic analyses were built in Figtree v.1.4.2 (http//tree.bio.ed.ac.uk/software/figtree).

\section{Results}

\section{Phylogenetic analyses}

The phylogenetic analyses of the four-locus (SSU+ITS+LSU+ $T E F 1)$ dataset comprising representatives of the Leptosphaeriaceae (and a member of the Cucurbitariaceae used as an outgroup) resulted in overall similar tree topologies 
Table 1 Species used for inferring the phylogeny of the Leptosphaeriaceae (and a member of the Cucurbitariaceae used as an outgroup) with details of their host, country of origin, strain or voucher information, GenBank accession numbers (ITS, LSU, SSU, TEF1) and references

\begin{tabular}{|c|c|c|c|c|c|c|c|}
\hline \multirow[t]{2}{*}{ Species } & \multirow[t]{2}{*}{ Host } & \multirow[t]{2}{*}{ Country } & \multirow{2}{*}{$\begin{array}{l}\text { Strain/ } \\
\text { voucher }\end{array}$} & \multicolumn{3}{|c|}{ GenBank acc. no. } & \multirow[t]{2}{*}{ References } \\
\hline & & & & ITS & LSU & $\mathrm{SSU} / T E F 1$ & \\
\hline $\begin{array}{l}\text { Alternariaster } \\
\text { bidentis }\end{array}$ & $\begin{array}{l}\text { Bidens } \\
\quad \text { sulphurea }\end{array}$ & Brazil & $\begin{array}{l}\text { CBS } \\
\quad 134021\end{array}$ & KC609333 & КC609341 & $-1-$ & Alves et al. 2013 \\
\hline $\begin{array}{l}\text { Alternariaster } \\
\text { bidentis }\end{array}$ & $\begin{array}{l}\text { Bidens } \\
\text { sulphurea }\end{array}$ & Brazil & $\begin{array}{l}\text { CBS } \\
134185\end{array}$ & KC609334 & KC609342 & $-1-$ & Alves et al. 2013 \\
\hline $\begin{array}{l}\text { Alternariaster } \\
\text { centaureae-- } \\
\text { diffusae }\end{array}$ & $\begin{array}{l}\text { Centaurea } \\
\quad \text { diffusa }\end{array}$ & Russia & $\begin{array}{l}\text { MFLUCC } \\
14-0992\end{array}$ & KT454723 & KT454715 & KT454730/- & Ariyawansa et al. 2015 \\
\hline $\begin{array}{l}\text { Alternariaster } \\
\quad \text { centaureae-- } \\
\text { diffusae }\end{array}$ & $\begin{array}{l}\text { Centaurea } \\
\text { diffusa }\end{array}$ & Russia & $\begin{array}{l}\text { MFLUC } \\
15-0009\end{array}$ & KT454724 & KT454716 & KT454731/- & Ariyawansa et al. 2015 \\
\hline $\begin{array}{l}\text { Alternariaster } \\
\text { helianthi }\end{array}$ & $\begin{array}{l}\text { Helianthus } \\
\text { annuus }\end{array}$ & Hungary & $\begin{array}{l}\text { CBS } \\
\quad 199.86\end{array}$ & KC609336 & KC609343 & $-1-$ & Alves et al. 2013 \\
\hline $\begin{array}{l}\text { Alternariaster } \\
\text { helianthi }\end{array}$ & $\begin{array}{l}\text { Helianthus } \\
\text { annuus }\end{array}$ & - & $\begin{array}{l}\text { CBS } \\
\quad 327.69\end{array}$ & KC609335 & КC584369 & KC584627/- & Alves et al. 2013 \\
\hline $\begin{array}{r}\text { Cucurbitaria } \\
\text { berberidis }\end{array}$ & $\begin{array}{l}\text { Berberis } \\
\quad \text { julianae }\end{array}$ & Netherlands & $\begin{array}{l}\text { CBS } \\
\quad 394.84\end{array}$ & - & JX681088 & GQ387544/- & $\begin{array}{l}\text { Verkley et al. } 2014 \text { (ITS); de Gruyter } \\
\text { et al. } 2010 \text { (LSU) }\end{array}$ \\
\hline $\begin{array}{l}\text { Heterospora } \\
\text { chenopodii }\end{array}$ & $\begin{array}{l}\text { Chenopodium } \\
\text { album }\end{array}$ & Netherlands & $\begin{array}{l}\text { CBS } \\
\quad 115.96\end{array}$ & JF740227 & EU754188 & EU754089/- & $\begin{array}{l}\text { de Gruyter et al. } 2013 \text { (ITS); de } \\
\text { Gruyter et al. } 2009 \text { (LSU, SSU) }\end{array}$ \\
\hline $\begin{array}{l}\text { Heterospora } \\
\text { chenopodii }\end{array}$ & $\begin{array}{l}\text { Chenopodium } \\
\text { album }\end{array}$ & Netherlands & $\begin{array}{l}\text { CBS } \\
\quad 448.68\end{array}$ & FJ427023 & EU754187 & EU754088/- & $\begin{array}{l}\text { Aveskamp et al. } 2009 \text { (ITS); de } \\
\text { Gruyter et al. } 2009 \text { (LSU, SSU) }\end{array}$ \\
\hline $\begin{array}{l}\text { Heterospora } \\
\text { dimorphospora }\end{array}$ & $\begin{array}{l}\text { Chenopodium } \\
\text { quinoa }\end{array}$ & Peru & $\begin{array}{l}\text { CBS } \\
\quad 165.78\end{array}$ & - & JF740281 & JF740098/- & de Gruyter et al. 2013 \\
\hline $\begin{array}{l}\text { Heterospora } \\
\quad \text { dimorphospora }\end{array}$ & $\begin{array}{l}\text { Chenopodium } \\
\text { quinoa }\end{array}$ & Peru & $\begin{array}{l}\text { CBS } \\
\quad 345.78\end{array}$ & - & GU238069 & GU238213/- & Aveskamp et al. 2010 \\
\hline $\begin{array}{l}\text { Leptosphaeria } \\
\quad \text { doliolum }\end{array}$ & dead stem & $\begin{array}{l}\text { United } \\
\text { Kingdo- } \\
\text { m }\end{array}$ & $\begin{array}{l}\text { MFLUC } \\
15-1875\end{array}$ & KT454727 & KT454719 & KT454734/- & Ariyawansa et al. 2015 \\
\hline $\begin{array}{l}\text { Leptosphaeria } \\
\text { doliolum }\end{array}$ & $\begin{array}{l}\text { Phlox } \\
\quad \text { paniculata }\end{array}$ & Netherlands & $\begin{array}{l}\text { CBS } \\
155.94\end{array}$ & JF740207 & JF740282 & $-1-$ & de Gruyter et al. 2013 \\
\hline $\begin{array}{l}\text { Leptosphaeria } \\
\quad \text { doliolum }\end{array}$ & Urtica dioica & Netherlands & $\begin{array}{l}\text { CBS } \\
\quad 505.75\end{array}$ & JF740205 & GQ387576 & GQ387515/GU349069 & $\begin{array}{l}\text { de Gruyter et al. } 2013 \text { (ITS); de } \\
\text { Gruyter et al. } 2010 \text { (LSU, SSU); } \\
\text { Schoch et al. } 2009 \text { (TEF1) }\end{array}$ \\
\hline $\begin{array}{l}\text { Leptosphaeria } \\
\text { doliolum }\end{array}$ & Rudbeckia & Netherlands & $\begin{array}{l}\text { CBS } \\
\quad 541.66\end{array}$ & JF740206 & JF740284 & $-1-$ & de Gruyter et al. 2013 \\
\hline $\begin{array}{l}\text { Leptosphaeria } \\
\text { errabunda }\end{array}$ & Solidago & Netherlands & $\begin{array}{l}\text { CBS } \\
\quad 617.75\end{array}$ & JF740216 & JF740289 & $-1-$ & de Gruyter et al. 2013 \\
\hline $\begin{array}{l}\text { Leptosphaeria } \\
\text { errabunda }\end{array}$ & Delphinium & Netherlands & $\begin{array}{l}\text { CBS } \\
\quad 125978\end{array}$ & JF740217 & JF740290 & $-1-$ & de Gruyter et al. 2013 \\
\hline $\begin{array}{c}\text { Leptosphaeria } \\
\text { pedicularis }\end{array}$ & Pedicularis & Switzerland & $\begin{array}{l}\text { CBS } \\
\quad 390.80\end{array}$ & JF740224 & JF740294 & $-1-$ & de Gruyter et al. 2013 \\
\hline $\begin{array}{l}\text { Leptosphaeria } \\
\text { pedicularis }\end{array}$ & $\begin{array}{l}\text { Gentiana } \\
\quad \text { punctata }\end{array}$ & Switzerland & $\begin{array}{l}\text { CBS } \\
\quad 126582\end{array}$ & JF740223 & JF740293 & $-1-$ & de Gruyter et al. 2013 \\
\hline $\begin{array}{l}\text { Leptosphaeria } \\
\text { sclerotioides }\end{array}$ & $\begin{array}{l}\text { Medicago } \\
\text { sativa }\end{array}$ & Canada & $\begin{array}{l}\text { CBS } \\
\quad 144.84\end{array}$ & JF740192 & JF740269 & $-1-$ & de Gruyter et al. 2013 \\
\hline $\begin{array}{l}\text { Leptosphaeria } \\
\text { sclerotioides }\end{array}$ & $\begin{array}{l}\text { Medicago } \\
\text { sativa }\end{array}$ & Canada & $\begin{array}{l}\text { CBS } \\
148.84\end{array}$ & JF740193 & JF740270 & $-1-$ & de Gruyter et al. 2013 \\
\hline $\begin{array}{l}\text { Leptosphaeria } \\
\text { slovacica }\end{array}$ & Ballota nigra & Netherlands & $\begin{array}{l}\text { CBS } \\
389.80\end{array}$ & JF740247 & JF740315 & JF740101/- & de Gruyter et al. 2013 \\
\hline $\begin{array}{l}\text { Leptosphaeria } \\
\text { slovacica }\end{array}$ & Ballota nigra & Netherlands & $\begin{array}{l}\text { CBS } \\
125975\end{array}$ & JF740248 & JF740316 & $-1-$ & de Gruyter et al. 2013 \\
\hline $\begin{array}{l}\text { Leptosphaeria } \\
\text { sydowii }\end{array}$ & $\begin{array}{l}\text { Senecio } \\
\quad \text { jacobaea }\end{array}$ & $\begin{array}{l}\text { United } \\
\text { Kingdo- } \\
\text { m }\end{array}$ & $\begin{array}{l}\text { CBS } \\
\quad 385.80\end{array}$ & JF740244 & JF740313 & $-/ J F 740139$ & de Gruyter et al. 2013 \\
\hline $\begin{array}{l}\text { Leptosphaeria } \\
\text { sydowii }\end{array}$ & $\begin{array}{l}\text { Senecio } \\
\quad \text { jacobaea }\end{array}$ & $\begin{array}{l}\text { United } \\
\text { Kingdo- } \\
\mathrm{m}\end{array}$ & $\begin{array}{l}\text { CBS } \\
\quad 125976\end{array}$ & JF740245 & JF740314 & $-1-$ & de Gruyter et al. 2013 \\
\hline $\begin{array}{l}\text { Paraleptosphaeria } \\
\quad \text { dryadis }\end{array}$ & $\begin{array}{l}\text { Dryas } \\
\quad \text { octopetala }\end{array}$ & Switzerland & $\begin{array}{l}\text { CBS } \\
\quad 643.86\end{array}$ & JF740213 & GU301828 & KC584632/GU349009 & $\begin{array}{l}\text { de Gruyter et al. } 2013 \text { (ITS); Schoch } \\
\text { et al. } 2009 \text { (LSU, TEF1); } \\
\text { Woudenberg et al. } 2013 \text { (SSU) }\end{array}$ \\
\hline $\begin{array}{l}\text { Paraleptosphaeria } \\
\text { dryadis }\end{array}$ & $\begin{array}{l}\text { Dryas } \\
\quad \text { octopetala }\end{array}$ & Switzerland & $\begin{array}{l}\text { CBS } \\
\quad 743.86\end{array}$ & AF439461 & - & $-1-$ & Camara et al. 2002 \\
\hline
\end{tabular}


Table 1 (continued)

\begin{tabular}{|c|c|c|c|c|c|c|c|}
\hline \multirow[t]{2}{*}{ Species } & \multirow[t]{2}{*}{ Host } & \multirow[t]{2}{*}{ Country } & \multirow{2}{*}{$\begin{array}{l}\text { Strain/ } \\
\text { voucher }\end{array}$} & \multicolumn{3}{|c|}{ GenBank acc. no. } & \multirow[t]{2}{*}{ References } \\
\hline & & & & ITS & LSU & $\mathrm{SSU} / T E F 1$ & \\
\hline $\begin{array}{l}\text { Paraleptosphaeria } \\
\text { macrospora }\end{array}$ & $\begin{array}{l}\text { Rumex } \\
\quad \text { longifolius }\end{array}$ & Norway & $\begin{array}{l}\text { CBS } \\
\quad 114198\end{array}$ & JF740238 & JF740305 & $-1-$ & de Gruyter et al. 2013 \\
\hline $\begin{array}{l}\text { Paraleptosphaeria } \\
\quad \text { nitschkei }\end{array}$ & $\begin{array}{l}\text { Cirsium } \\
\quad \text { spinosissim- } \\
\text { um }\end{array}$ & Switzerland & $\begin{array}{l}\text { CBS } \\
\quad 306.51\end{array}$ & $\begin{array}{l}\text { NR_111621 } \\
(=J- \\
\text { F740239) }\end{array}$ & JF740308 & $-1-$ & de Gruyter et al. 2013 \\
\hline $\begin{array}{l}\text { Paraleptosphaeria } \\
\text { nitschkei }\end{array}$ & Petasites & Italy & $\begin{array}{l}\text { MFLU } \\
13-0644\end{array}$ & KP729446 & KP729447 & $-1-$ & Liu et al. 2015 \\
\hline $\begin{array}{l}\text { Paraleptosphaeria } \\
\text { polylepidis }\end{array}$ & $\begin{array}{l}\text { Polylepis } \\
\quad \text { tarapacana }\end{array}$ & Bolivia & $\begin{array}{l}\text { MA-Fungi } \\
57843- \\
\text { holotype }\end{array}$ & AJ786644 & - & $-1-$ & Macia et al. 2005 \\
\hline $\begin{array}{l}\text { Paraleptosphaeria } \\
\text { polylepidis }\end{array}$ & $\begin{array}{l}\text { Polylepis } \\
\quad \text { tarapacana }\end{array}$ & Bolivia & APA-2999 & MK795714 & MK795717 & MK795720/MK831009 & This study \\
\hline $\begin{array}{l}\text { Paraleptosphaeria } \\
\text { praetermissa }\end{array}$ & Rubus idaeus & Sweden & $\begin{array}{l}\text { CBS } \\
\quad 114591\end{array}$ & JF740241 & JF740310 & $-1-$ & de Gruyter et al. 2013 \\
\hline $\begin{array}{l}\text { Paraleptosphaeria } \\
\text { rubi }\end{array}$ & Rubus & Italy & $\begin{array}{l}\text { MFLUCC } \\
14-0211\end{array}$ & KT454726 & KT454718 & KT454733/- & Ariyawansa et al. 2015 \\
\hline $\begin{array}{l}\text { Paraleptosphaeria } \\
\text { sp. (as } \\
\text { Leptosphaeria } \\
\text { sp.) }\end{array}$ & $\begin{array}{l}\text { Phlomis } \\
\quad \text { younghusba- } \\
\quad \text { ndii }\end{array}$ & China & PHY-06 & JX401979 & JX401985 & $-1-$ & Zhang D.W. and Guo S.X. unpubl. \\
\hline $\begin{array}{l}\text { Paraleptosphaeria } \\
\text { sp. (as } \\
\text { Leptosphaeria } \\
\text { sp.) }\end{array}$ & $\begin{array}{l}\text { Phlomis } \\
\quad \text { younghusba- } \\
\quad \text { ndii }\end{array}$ & China & PHY-54 & JX401931 & JX401999 & $-1-$ & Zhang D.W. and Guo S.X. unpubl. \\
\hline $\begin{array}{l}\text { Plenodomus } \\
\quad \text { biglobosus }\end{array}$ & Brassica juncea & France & $\begin{array}{l}\text { CBS } \\
\quad 127249\end{array}$ & JF740199 & JF740275 & $-1-$ & de Gruyter et al. 2013 \\
\hline $\begin{array}{l}\text { Plenodomus } \\
\quad \text { biglobosus }\end{array}$ & $\begin{array}{l}\text { Brassica napus } \\
\quad \text { var. } \\
\quad \text { napobrassic- } \\
\quad a\end{array}$ & - & $\begin{array}{l}\text { CBS } \\
298.36\end{array}$ & AJ550862 & GU237980 & GU238207/- & $\begin{array}{l}\text { Mendes-Pereira et al. } 2003 \text { (ITS); } \\
\text { Aveskamp et al. } 2010 \text { (LSU, SSU) }\end{array}$ \\
\hline Plenodomus lupini & $\begin{array}{l}\text { Lupinus } \\
\quad \text { mutabilis }\end{array}$ & Peru & $\begin{array}{l}\text { CBS } \\
248.92\end{array}$ & JF740236 & JF740303 & $-1-$ & de Gruyter et al. 2013 \\
\hline $\begin{array}{l}\text { Plenodomus } \\
\text { pimpinellae }\end{array}$ & $\begin{array}{l}\text { Pimpinella } \\
\text { anisum }\end{array}$ & Israel & $\begin{array}{l}\text { CBS } \\
101637\end{array}$ & JF740240 & JF740309 & $-1-$ & de Gruyter et al. 2013 \\
\hline $\begin{array}{l}\text { Plenodomus } \\
\text { salviae }\end{array}$ & Salvia glutinosa & Italy & $\begin{array}{l}\text { MFLUCC } \\
13-0219\end{array}$ & KT454725 & KT454717 & KT454732/- & Ariyawansa et al. 2015 \\
\hline $\begin{array}{l}\text { Plenodomus sp. (as } \\
\text { Leptosphaeria } \\
s p . \text {.) }\end{array}$ & $\begin{array}{l}\text { Phlomis } \\
\quad \text { younghusba- } \\
\text { ndii }\end{array}$ & China & PHY-30 & JX401955 & JX401989 & $-1-$ & Zhang D.W. and Guo S.X. unpubl. \\
\hline Plenodomus visci & Viscum album & France & $\begin{array}{l}\text { CBS } \\
\quad 122783\end{array}$ & - & EU754195 & EU754096/- & de Gruyter et al. 2009 \\
\hline $\begin{array}{r}\text { Plenodomus } \\
\text { wasabiae }\end{array}$ & $\begin{array}{l}\text { Eutrema } \\
\quad \text { japonicum }\end{array}$ & Taiwan & $\begin{array}{l}\text { CBS } \\
\quad 120119\end{array}$ & JF740257 & JF740323 & $-1-$ & de Gruyter et al. 2013 \\
\hline $\begin{array}{l}\text { Plenodomus } \\
\text { wasabiae }\end{array}$ & $\begin{array}{l}\text { Eutrema } \\
\quad \text { japonicum }\end{array}$ & Taiwan & $\begin{array}{l}\text { CBS } \\
\quad 120120\end{array}$ & JF740258 & JF740324 & $-1-$ & de Gruyter et al. 2013 \\
\hline $\begin{array}{l}\text { Subplenodomus } \\
\quad \text { violicola }\end{array}$ & Viola tricolor & Netherlands & $\begin{array}{l}\text { CBS } \\
\quad 306.68\end{array}$ & FJ427083 & GU238156 & $-1-$ & $\begin{array}{l}\text { Aveskamp et al. } 2009 \text { (ITS); } \\
\quad \text { Aveskamp et al. } 2010 \text { (LSU) }\end{array}$ \\
\hline $\begin{array}{l}\text { Subplenodomus } \\
\quad \text { violicola }\end{array}$ & Viola tricolor & $\begin{array}{l}\text { New } \\
\quad \text { Zealand }\end{array}$ & $\begin{array}{l}\text { CBS } \\
\quad 100272\end{array}$ & FJ427082 & JF740322 & $-1-$ & $\begin{array}{l}\text { Aveskamp et al. } 2009 \text { (ITS); de } \\
\text { Gruyter et al. } 2013 \text { (LSU) }\end{array}$ \\
\hline
\end{tabular}

APA A. N. Palabral-Aguilera; CBS CBS-KNAW Collections, Westerdijk Fungal Biodiversity Institute, Utrecht, The Netherlands; MA Real Jardín Botánico herbarium, Madrid, Spain; MFLU Mae Fah Luang University herbarium; MFLUCC Mae Fah Luang University Culture Collection, Chiang Rai, Thailand

obtained from BI and ML analyses. The Heterospora clade nested together with Subplenodomus in the ML analysis but was sister to the remaining genera of the Leptosphaeriaceae in $\mathrm{BI}$ analysis. In general, high bootstrap support values above $70 \%$ (ML-BP) and posterior probabilities above 0.95 (PP) were retrieved and supported monophyletic lineages representing distinct genera as in previous studies (de Gruyter et al. 2013; Ariyawansa et al. 2015; Tibpromma et al. 2017). The Bayesian tree is displayed in Fig. 1. The newly generated Leptosphaeria polylepidis sequences clustered with ex-holotype sequence of L. polylepidis (ML-BP $=100 \%, \mathrm{PP}=1$ ) in their well-supported Paraleptosphaeria lineage $(\mathrm{ML}-\mathrm{BP}=78 \%, \mathrm{PP}=1)$; 
relatedness of L. polylepidis and Paraleptosphaeria dryadis was weakly supported $(\mathrm{ML}-\mathrm{BP}=60 \%)$. The ITS sequence from the newly generated material and holotype of L. polylepidis differed in $6 \mathrm{bp}$. The SSU, LSU, and TEF1 sequences were not available from holotype material.

The phylogenetic analyses of the two-locus (ITS+LSU) dataset, including representatives of the Dictyosporiaceae and two sequences of Periconia igniaria used as an outgroup, resulted in similar tree topologies. Dictyosporium grouped in a single clade together with Aquadictyospora in ML analysis but was sister to the Pseudodictyosporium lineage in the BI analysis. The Bayesian consensus tree is displayed in Fig. 2. The phylogenetic tree shows 11 monophyletic lineages of the Dictyosporiaceae, corresponding to 10 known genera and one unknown lineage, the latter of which consisted of the conidiomatal fungus from Leptosphaeria polylepidis. Results were roughly consistent with previous phylogenetic results (e.g., Iturrieta-González et al. 2018; Yang et al. 2018), except for some differences in branches with low statistical support values mainly at the backbone of the phylogenetic tree. The sequences of the conidiomatal fungus from two independent extraction rounds were identical and of high quality, excluding the possibility of DNA isolation from contaminating fungi, and were nested within the currently circumscribed family Dictyosporiaceae $(\mathrm{ML}-\mathrm{BP}=100 \%, \mathrm{PP}=1)$. They formed a sister group to the members of the genus Pseudocoleophoma $(\mathrm{ML}-\mathrm{BP}=89 \%, \mathrm{PP}=1)$. The phylogenetic relationships of the conidiomatal fungus and the Pseudocoleophoma lineage with their relatives in the Dictyosporiaceae remain unresolved, due the lack of support in our molecular analyses.

\section{Taxonomy}

Paraleptosphaeria polylepidis (M.J. Macía, M.E. Palm \& M.P. Martín) Piątek, Flakus \& Rodr. Flakus, comb. nov. (Fig. 3)

\section{MycoBank no. MB832195}

Basionym: Leptosphaeria polylepidis M.J. Macía, M.E. Palm \& M.P. Martín, Mycotaxon 93: 402 (2005)

Ascomata pseudothecial, developed on stroma. Stroma 1-3 $\mathrm{mm}$ high, 2-7 $\mathrm{mm}$ wide, black, surface with visible individual pseudothecia, usually with base growing inward and intermixed with host tissue. Pseudothecia dark brown to black, matt, rough, 300-700 $\mu \mathrm{m}$ high, 300-600 $\mu \mathrm{m}$ wide, globose to subglobose with base usually protruding into ca. $200-1000 \mu \mathrm{m}$ high stipes that fuse below into stroma; papillae short or lacking. Peridium 60-150 $\mu \mathrm{m}$ wide, pale to dark brown ( $\mathrm{KOH}+$ greenish grey), consisting of a single stratum, paraplectenchymatous, textura angularis, composed of several layers of isodiametric to slightly elongate thin-walled cells, $15-25 \times 9-15 \mu \mathrm{m}$. Hamathecium persistent, composed of relatively thin, 1.5-4 $\mu \mathrm{m}$ wide, septate, branched and strongly anastomosed pseudoparaphyses. Asci 120-250 × 20-45 $\mu \mathrm{m}, 5-8$-spored, bitunicate, cylindrical- clavate, slightly curved, with a short stipe, apically widened, with an ocular chamber, IKI-, $\mathrm{KOH} / \mathrm{IKI}-$; endosacus $\mathrm{KOH} /$ IKI+ orange. Ascospores 45-60 × (14-)20-23 $\mu \mathrm{m}$, pale brown, broadly ellipsoidal, narrower at the top, constricted at septa, uniformly thin-walled, without perispore or gelatinous coat, (2-)3(-4)-septate. Asexual state unknown.

Specimen examined (used for morphology and molecular analyses): See host fungus in the type of Sajamaea mycophila.

Additional specimens examined: Bolivia, Oruro, Sajama National Park (=Parque Nacional Sajama), W slope of Sajama's volcano, Quebrada Huaytana, 18 $11^{\prime}$ S, 68 $51^{\prime}$ W, elev. ca. 4000-4200 m, on Polylepis tarapacana, 1 Feb. 2016, A. Domic (three collections: $A D 1, A D 2, A D 5$; all in LPB).

Sajamaea Flakus, Piątek \& Rodr. Flakus, gen. nov. MycoBank no. MB832196

Etymology: Referring to the place of occurrence of the new genus - slopes of Nevado Sajama, the highest mountain in Bolivia.

Description: Mycoparasitic. Conidiomata pycnidial, uniloculate to multi-loculate, subglobose to irregular in shape, pale brown. Peridium composed of several layers of isodiametric to slightly elongate cells in the form of textura angularis. Conidiophores hyaline, reduced to phialidic conidiogenous cells. Conidia pigmented (pale brown), broadly ellipsoidal, aseptate, smooth, thin-walled, guttulate. Generic type: Sajamaea mycophila Flakus, M. Piątek \& Rodr. Flakus.

Sajamaea mycophila Flakus, Piątek \& Rodr. Flakus, sp. nov. (Fig. 4)

MycoBank no. MB832197

Etymology: The epithet name mycophila refers to the occurrence of this fungus on other fungus.

Description: Mycoparasitic on Paraleptosphaeria polylepidis, causing moderate damages of host ascomata. Conidiomata pycnidial, as pale brown galls on host surface, 150-300 $\mu \mathrm{m}$ wide, 120-300 $\mu \mathrm{m}$ high, first erumpent through the outermost layer of host peridium, later almost sessile on pseudothecial clusters of host, uniloculate to multi-loculate, solitary to aggregated, subglobose to irregular in shape, pale brown; better seen when wet. Peridium 20-30 $\mu \mathrm{m}$ wide, pale to dark brown, composed of about 3-8 layers of cells with walls up to $2 \mu \mathrm{m}$ wide, cells isodiametric to slightly elongate, textura angularis. Conidiophores reduced to conidiogenous cells. Conidiogenous cells 5-11 $\mu \mathrm{m}$ high, 4-8 $\mu \mathrm{m}$ wide, enteroblastic, phialidic, smooth-walled, hyaline, with a small collar, densely outlining inner surfaces of pycnidia. Conidia 9-13 $\times 5.5-7.5 \mu \mathrm{m}$, pale brown, broadly ellipsoidal, sometimes slightly narrower at one point, with rounded ends, aseptate, smooth, thin-walled, guttulate. Sexual state unknown.

Specimen examined: Bolivia, Oruro, Sajama National Park (=Parque Nacional Sajama), W slope of Nevado Sajama, 
Table 2 Species used for inferring phylogeny of the Dictyosporiaceae (and Periconia igniaria used as an outgroup) with details of their substrate or host, country of origin, strain or voucher information, GenBank accession numbers (ITS, LSU), and references

\begin{tabular}{|c|c|c|c|c|c|c|}
\hline \multirow[t]{2}{*}{ Species } & \multirow[t]{2}{*}{ Substrate/host } & \multirow[t]{2}{*}{ Country } & \multirow[t]{2}{*}{ Strain/voucher } & \multicolumn{2}{|c|}{ GenBank acc. no. } & \multirow[t]{2}{*}{ References } \\
\hline & & & & ITS & LSU & \\
\hline $\begin{array}{l}\text { Aquadictyospora } \\
\quad \text { lignicola }\end{array}$ & Submerged wood & China & MFLUCC 17-1318 & MF948621 & MF948629 & Li et al. 2017 \\
\hline $\begin{array}{l}\text { Cheirosporium } \\
\text { triseriale }\end{array}$ & Submerged wood & China & HMAS 180703 & EU413953 & EU413954 & Cai et al. 2008 \\
\hline $\begin{array}{l}\text { Dendryphiella } \\
\text { paravinosa }\end{array}$ & $\begin{array}{l}\text { Leaves of Citrus } \\
\quad \text { sinensis }\end{array}$ & Italy & CBS 14128 & KX228257 & KX228309 & Crous et al. 2016 \\
\hline $\begin{array}{l}\text { Dendryphiella } \\
\text { variabilis }\end{array}$ & $\begin{array}{l}\text { Dead leaf of a } \\
\text { lauraceous tree }\end{array}$ & Cuba & CBS 584.96 & LT963453 & LT963454 & $\begin{array}{l}\text { Iturrieta-González et al. } \\
2018\end{array}$ \\
\hline Dendryphiella vinosa & - & $\begin{array}{l}\text { Japan (for ITS, } \\
\text { unavailable } \\
\text { for LSU) }\end{array}$ & $\begin{array}{l}\text { NBRC } 32669 \text { (for ITS, } \\
\text { strain info unavailable } \\
\text { for LSU) }\end{array}$ & DQ307316 & EU848590 & $\begin{array}{l}\text { Dela Cruz T.E. et al. unpubl. } \\
\text { (ITS); Jones et al. } 2008 \\
\text { (LSU) }\end{array}$ \\
\hline $\begin{array}{l}\text { Dictyocheirospora } \\
\text { aquatica }\end{array}$ & Submerged wood & China & KUMCC 15-0305 & KY320508 & KY320513 & Wang et al. 2016 \\
\hline $\begin{array}{l}\text { Dictyocheirospora } \\
\text { bannica }\end{array}$ & Dead wood & Japan & KH 332 & LC014543 & AB807513 & Tanaka et al. 2015 \\
\hline $\begin{array}{l}\text { Dictyocheirospora } \\
\quad \text { rotunda }\end{array}$ & $\begin{array}{l}\text { Submerged dead } \\
\text { decaying wood }\end{array}$ & Thailand & MFLUCC 14-0293 & KU179099 & KU179100 & Boonmee et al. 2016 \\
\hline $\begin{array}{l}\text { Dictyocheirospora } \\
\quad \text { rotunda }\end{array}$ & Submerged wood & China & $\begin{array}{l}\text { MFLUCC 17-1313 (in } \\
\text { GenBank) or } \\
\text { MFLUCC 17-1687 (in } \\
\text { publication) }\end{array}$ & MF948625 & MF948633 & Li et al. 2017 \\
\hline $\begin{array}{l}\text { Dictyosporium } \\
\text { bulbosum }\end{array}$ & Dead wood & Japan & yone 221 & LC014544 & AB807511 & Tanaka et al. 2015 \\
\hline $\begin{array}{l}\text { Dictyosporium } \\
\quad \text { elegans }\end{array}$ & - & - & NBRC 32502 & DQ018087 & DQ018100 & Tsui et al. 2006 \\
\hline $\begin{array}{l}\text { Dictyosporium } \\
\text { thailandicum }\end{array}$ & Submerged wood & Thailand & MFLUCC 13-0773 & KP716706 & KP716707 & Liu et al. 2015 \\
\hline $\begin{array}{l}\text { Dictyosporium } \\
\text { toruloides }\end{array}$ & - & - & CBS 209.65 & DQ018093 & DQ018104 & Tsui et al. 2006 \\
\hline $\begin{array}{r}\text { Digitodesmium } \\
\text { bambusicola }\end{array}$ & - & - & CBS 110279 & DQ018091 & DQ018103 & Tsui et al. 2006 \\
\hline $\begin{array}{l}\text { Gregarithecium } \\
\text { curvisporum }\end{array}$ & $\begin{array}{l}\text { Dead culms of Sasa } \\
\text { sp. }\end{array}$ & Japan & KT 922 & AB809644 & $\mathrm{AB} 807547$ & Tanaka et al. 2015 \\
\hline Jalapriya inflata & Piece of driftwood & United Kindom & NTOU 3855 & JQ267362 & JQ267363 & Kirschner et al. 2013 \\
\hline Jalapriya pulchra & $\begin{array}{l}\text { Submerged decaying } \\
\text { wood }\end{array}$ & China & MFLUCC 15-0348 & KU179108 & KU179109 & Boonmee et al. 2016 \\
\hline Jalapriya pulchra & Submerged wood & China & MFLUCC 17-1683 & MF948628 & MF948636 & Li et al. 2017 \\
\hline $\begin{array}{l}\text { Neodendryphiella } \\
\quad \text { mali }\end{array}$ & $\begin{array}{l}\text { Leaf of Malus } \\
\quad \text { domestica }\end{array}$ & Italy & CBS 139.95 & LT906655 & LT906657 & $\begin{array}{l}\text { Iturrieta-González et al. } \\
2018\end{array}$ \\
\hline $\begin{array}{l}\text { Neodendryphiella } \\
\quad \text { mali }\end{array}$ & Herbivore dung & Spain & FMR 17003 & LT993734 & LT993735 & $\begin{array}{l}\text { Iturrieta-González et al. } \\
2018\end{array}$ \\
\hline $\begin{array}{l}\text { Neodendryphiella } \\
\text { michoacanensis }\end{array}$ & Soil & Mexico & FMR 16098 & LT906660 & LT906658 & $\begin{array}{l}\text { Iturrieta-González et al. } \\
\quad 2018\end{array}$ \\
\hline $\begin{array}{l}\text { Neodendryphiella } \\
\text { tarraconensis }\end{array}$ & Soil & Spain & FMR 16234 & LT906659 & LT906656 & $\begin{array}{l}\text { Iturrieta-González et al. } \\
\quad 2018\end{array}$ \\
\hline Periconia igniaria & Triticum aestivum & Switzerland & CBS 379.86 & LC014585 & AB807566 & Tanaka et al. 2015 \\
\hline Periconia igniaria & Bamboo & $\begin{array}{l}\text { Papua New } \\
\text { Guinea }\end{array}$ & CBS 845.96 & LC014586 & AB807567 & Tanaka et al. 2015 \\
\hline $\begin{array}{l}\text { Pseudocoleophoma } \\
\text { calamagrostidis }\end{array}$ & $\begin{array}{l}\text { Dead leaves of } \\
\text { Calamagrostis } \\
\text { matsumurae }\end{array}$ & Japan & KT 3284 & LC014592 & LC014609 & Tanaka et al. 2015 \\
\hline \multirow[t]{2}{*}{$\begin{array}{l}\text { Pseudocoleophoma } \\
\text { polygonicola }\end{array}$} & $\begin{array}{l}\text { Dead stems of } \\
\text { polygonaceous } \\
\text { plant }\end{array}$ & Japan & KT 731 & AB809634 & AB807546 & Tanaka et al. 2015 \\
\hline & & United Kingdom & MFLUCC 16-0123 & KX576655 & KX576656 & Hyde et al. 2016 \\
\hline
\end{tabular}


Table 2 (continued)

\begin{tabular}{|c|c|c|c|c|c|c|}
\hline \multirow[t]{2}{*}{ Species } & \multirow[t]{2}{*}{ Substrate/host } & \multirow[t]{2}{*}{ Country } & \multirow[t]{2}{*}{ Strain/voucher } & \multicolumn{2}{|c|}{ GenBank acc. no. } & \multirow[t]{2}{*}{ References } \\
\hline & & & & ITS & LSU & \\
\hline $\begin{array}{l}\text { Pseudocoleophoma } \\
\text { typhicola }\end{array}$ & $\begin{array}{l}\text { Submerged stems of } \\
\text { Typha latifolia }\end{array}$ & & & & & \\
\hline $\begin{array}{l}\text { Pseudodictyosporium } \\
\text { elegans }\end{array}$ & - & - & CBS 688.93 & DQ018099 & DQ018106 & Tsui et al. 2006 \\
\hline $\begin{array}{l}\text { Pseudodictyosporium } \\
\text { thailandica }\end{array}$ & $\begin{array}{l}\text { Decaying bamboo } \\
\text { stem }\end{array}$ & Thailand & MFLUCC 16-0029 & KX259520 & KX259522 & Hyde et al. 2016 \\
\hline $\begin{array}{l}\text { Pseudodictyosporium } \\
\text { wauense }\end{array}$ & - & - & NBRC 30078 & DQ018098 & DQ018105 & Tsui et al. 2006 \\
\hline Sajamaea mycophila & $\begin{array}{l}\text { Pseudothecia of } \\
\text { Paraleptosphaeria } \\
\text { polylepidis }\end{array}$ & Bolivia & $\begin{array}{l}\text { APA-2999 (DNA isolated } \\
\text { from conidial mass) }\end{array}$ & MK795715 & MK795718 & This study \\
\hline Sajamaea mycophila & $\begin{array}{l}\text { Pseudothecia of } \\
\text { Paraleptosphaeria } \\
\text { polylepidis }\end{array}$ & Bolivia & $\begin{array}{l}\text { APA-2999 (DNA isolated } \\
\text { from conidiomata) }\end{array}$ & MK795716 & MK795719 & This study \\
\hline
\end{tabular}

APA A. N. Palabral-Aguilera; CBS CBS-KNAW Collections, Westerdijk Fungal Biodiversity Institute, Utrecht, The Netherlands; FMR Facultat de Medicina i Ciencies de la Salut, Reus, Spain; HMAS Herbarium Mycologium Institute of Microbiology Chinese Academy of Sciences, Beijing, China; $K H$ K. Hirayama; KT K. Tanaka; KUMCC Culture collection of Kunming Institute of Botany, Kunming, China; MFLUCC Mae Fah Luang University Culture Collection, Chiang Rai, Thailand; NBRC National Institute of Technology and Evaluation, Chiba, Japan; NTOU National Taiwan Ocean University Culture Collection, Keelung, Taiwan; yone H. Yonezawa

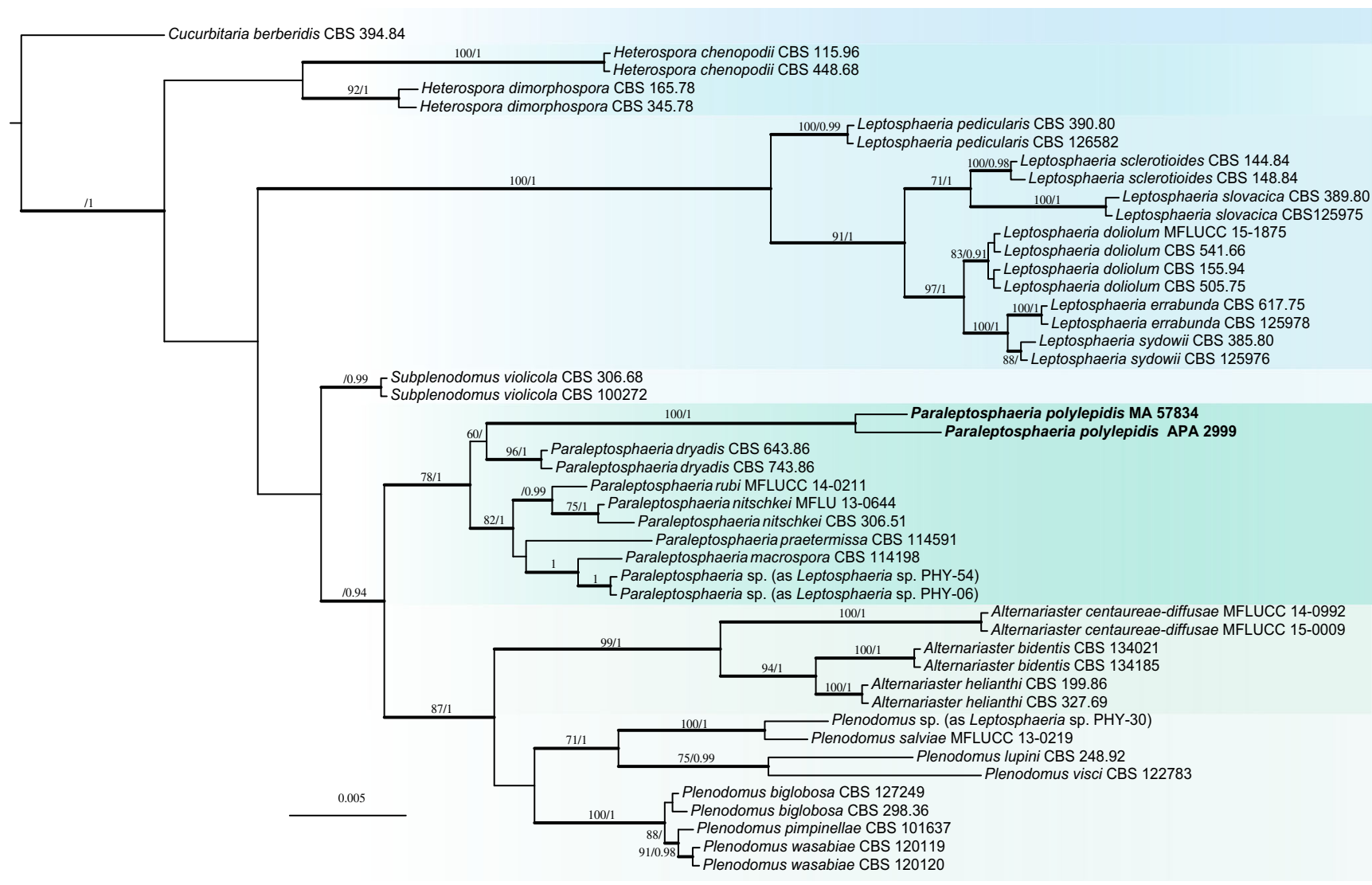

Fig. 1 Bayesian inference consensus tree inferred from a four-locus dataset $(\mathrm{SSU}+\mathrm{ITS}+\mathrm{LSU}+T E F 1)$ of the Leptosphaeriaceae clade. Numbers above bold branches indicate bootstrap support values $\geq 70 \%$ from maximum likelihood and posterior probabilities $\geq 0.95$ from Bayesian inference analyses. Cucurbitaria berberidis is used as an outgroup 


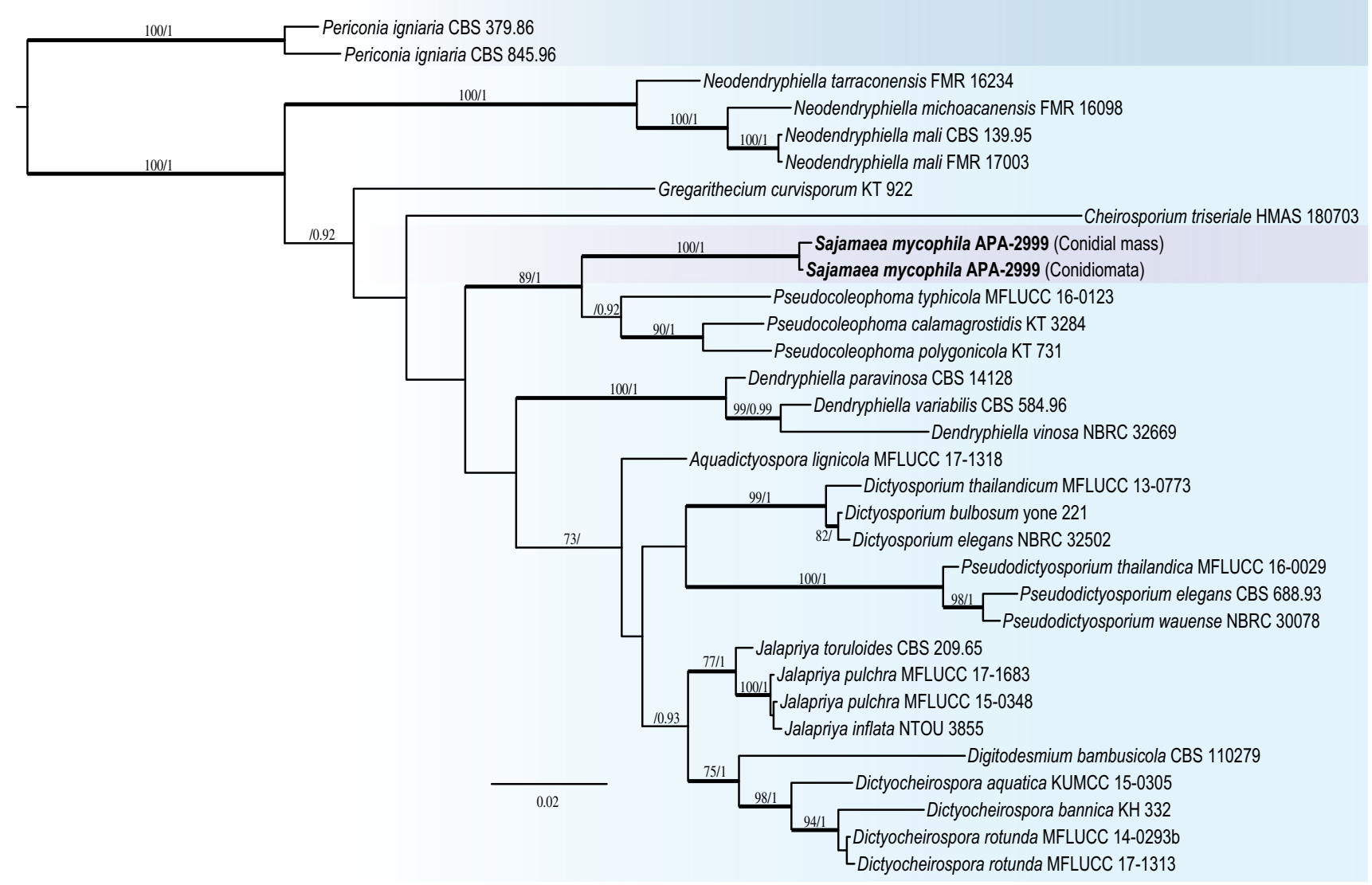

Fig. 2 Bayesian inference consensus tree inferred from two-locus dataset (ITS+LSU) of the Dictyosporiaceae clade. Numbers above bold branches indicate bootstrap support values $\geq 70 \%$ from maximum likelihood and

closely located to the permanent monitoring plot "Cohiri," 19K 512102, 8002927, elev. ca. $4425 \mathrm{~m}$, parasitic on Paraleptosphaeria polylepidis growing on Polylepis tarapacana, 15 Oct. 2016, A.N. Palabral-Aguilera (APA2999), C. López \& M.I. Gómez (LPB 0003512 - holotype, KRAM F-59659 - isotype).

\section{Discussion}

Molecular phylogenetic analyses, based on the four-gene dataset, placed Leptosphaeria polylepidis in a wellsupported clade consisting of members of the genus Paraleptosphaeria, including the type species $\mathrm{Pa}$. nitschkei. The genus Paraleptosphaeria has been described by de Gruyter et al. (2013) for Pa. dryadis, Pa. macrospora, Pa. nitschkei, Pa. orobanches, and $P a$. praetermissa that form a distinct monophyletic lineage among Leptosphaeriaceae within Pleosporales. Paraleptosphaeria is morphologically similar but clearly divergent genetically from the Leptosphaeria lineage. Separateness of Paraleptosphaeria from Leptosphaeria has been confirmed by subsequent molecular studies posterior probabilities $\geq 0.9$ from Bayesian inference analyses. Periconia igniaria is used as an outgroup

(Ariyawansa et al. 2015; Chen et al. 2015; Liu et al. 2015; Wanasinghe et al. 2016; Tibpromma et al. 2017); additionally, two novel species, $P a$. padi and $P a$. rubi, have been described in the genus (Ariyawansa et al. 2015; Tibpromma et al. 2017) after its original establishment. Therefore, prior to this study, seven species were accepted in Paraleptosphaeria.

The generic concept of Paraleptosphaeria includes species having immersed, solitary or aggregated, thick-walled, ostiolate and unilocular pseudothecia, bitunicate, 8-spored asci, and fusiform, 5-8-septate, hyaline to yellow-brownish ascospores. The asexual state, when present, is coelomycetous consisting of pycnidial, unilocular conidiomata, phialidic conidiogeneous cells, and oblong or ellipsoidal, aseptate, hyaline conidia (de Gruyter et al. 2013). Leptosphaeria polylepidis generally fits well to this concept, except that its pseudothecia are superficial and developed on stroma. However, this character may be variable in the genus, and, for example, Liu et al. (2015) reported superficial pseudothecia in their material of Paraleptosphaeria nitschkei. Therefore, based on molecular evidence, Leptosphaeria polylepidis is transferred to Paraleptosphaeria (as $\mathrm{Pa}$. polylepidis) in this study. 

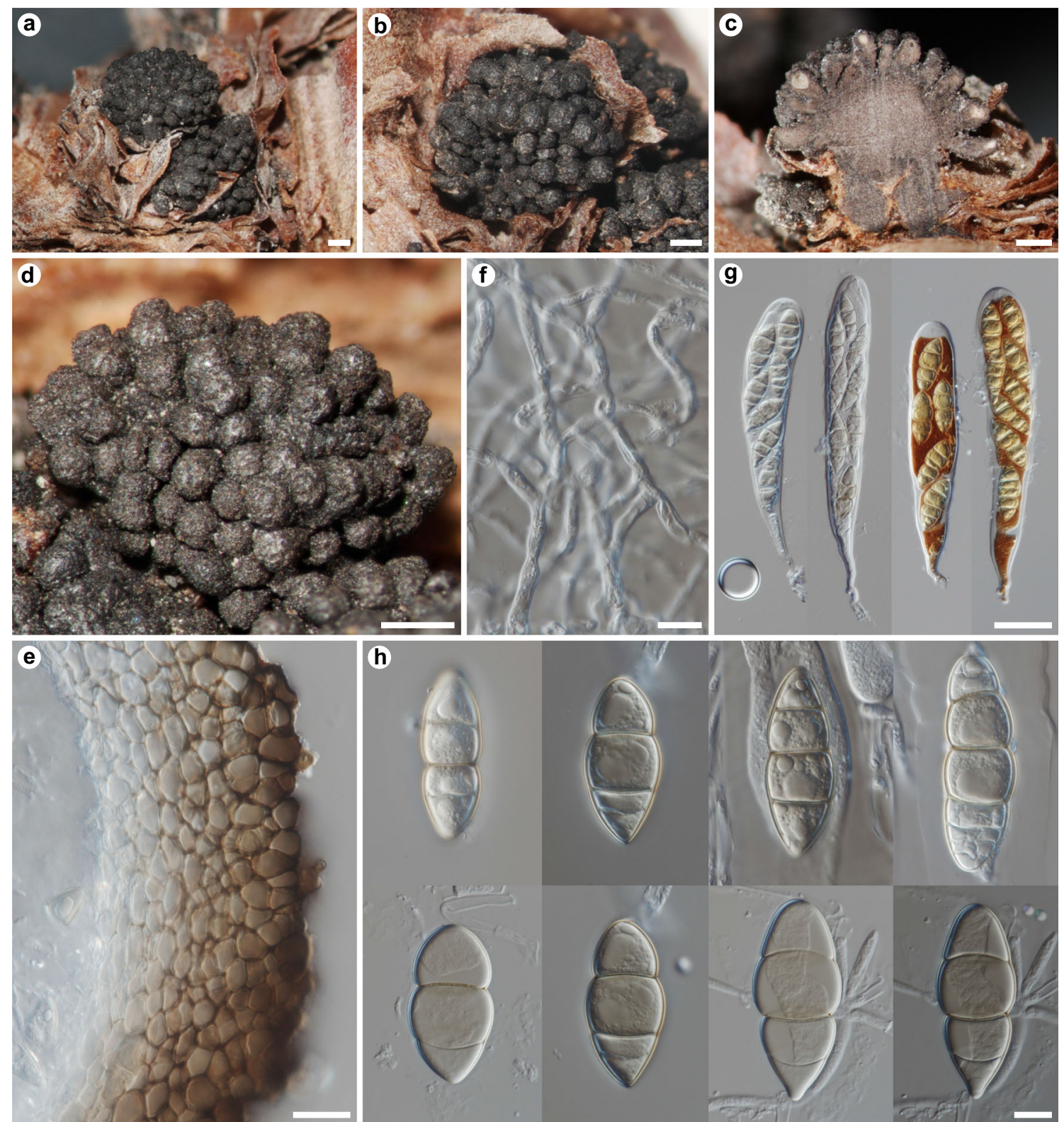

Fig. 3 Paraleptosphaeria polylepidis (KRAM F-59659). a, b, d Habit of the crowded ascomata on twig of Polylepis tarapacana. c Longitudinal section through ascomata and stroma. e Paraplectenchymatous peridium from longitudinal section. f Hamathecium composed of thin interascal

Other than genetically divergent, Paraleptosphaeria may be ecologically different from Leptosphaeria by having other host specialization. Five of the eight Paraleptosphaeria species occur on Rosaceae, and three species on other host families, Asteraceae, Orobanchaceae, and Polygonaceae, while Leptosphaeria species tend to inhabit hosts in very diverse families but not Rosaceae (de Gruyter et al. 2013; Ariyawansa et al. 2015; Dayarathne et al. 2015; Liu et al. 2015). The molecular phylogenetic analyses showed that Paraleptosphaeria polylepidis was weakly supported as sister species of $\mathrm{Pa}$. dryadis supporting earlier finding

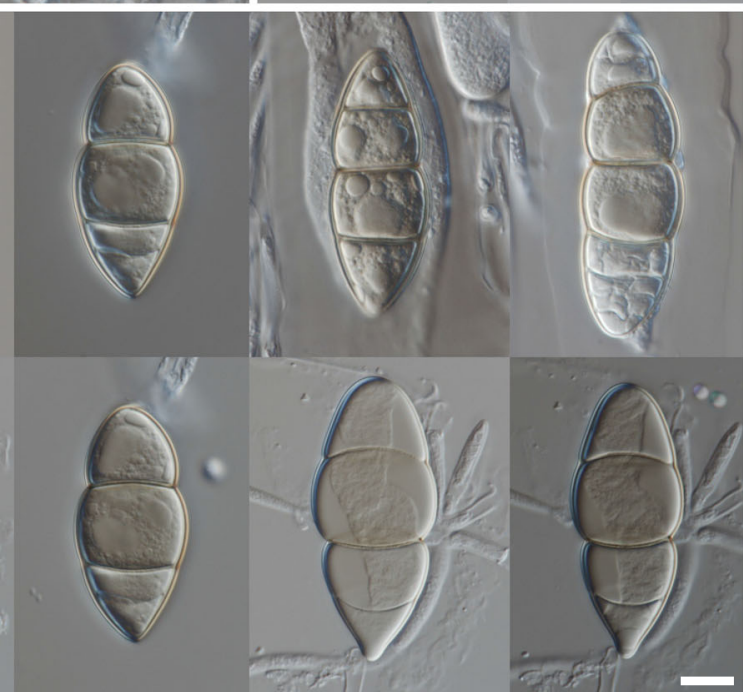

filaments. g Bitunicate asci with 5-8 ascospores inside (left mounted in water, right mounted in $\mathrm{KOH} / \mathrm{IKI}$ ). $\mathbf{h}$ Ascospores mounted in water. Scale bars: a-d $500 \mu \mathrm{m}, \mathbf{e} 25 \mu \mathrm{m}, \mathbf{f}, \mathbf{h} 10 \mu \mathrm{m}, \mathbf{g} 50 \mu \mathrm{m}$

by Macía et al. (2005). These authors pointed out that $P a$. polylepidis and $P a$. dryadis occur both at high elevations. Their host plants, Polylepis tarapacana and Dryas octopetala (Rosaceae), are adapted to grow in cold ecosystems. According to our molecular analyses, the branch leading to $\mathrm{Pa}$. polylepidis is very long, which may suggest an old evolutionary origin of this lineage. It is, however, also possible that undiscovered closely related Paraleptosphaeria species may still exist in poorly studied South American countries. The weakly supported sister-group relationship of $\mathrm{Pa}$. polylepidis and $P a$. dryadis and the circumstance that their hosts 

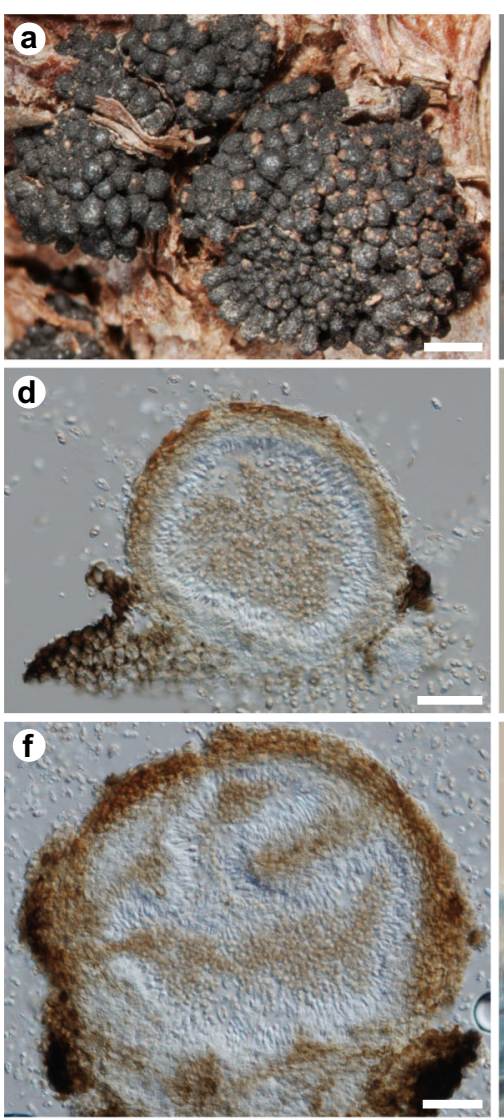

(i)
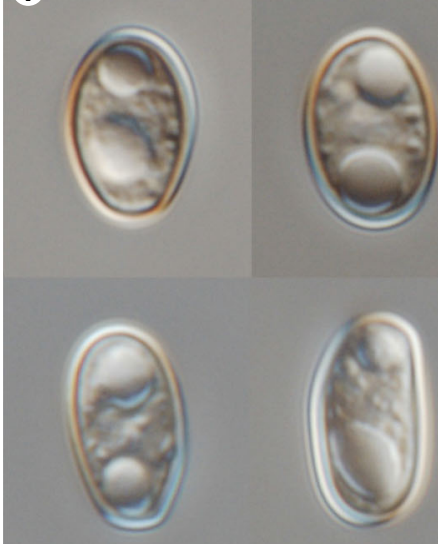

Fig. 4 Sajamaea mycophila (KRAM F-59659). a-c Habit of pale brown conidiomata growing on ascomata of Paraleptosphaeria polylepidis. d-e Longitudinal section of uniloculate conidioma erumpent through the outermost layer of host peridium (e mounted in LPCB). f Longitudinal section of multi-loculate conidioma showing layers of conidiogenous

are phylogenetically unrelated (Potter et al. 2007) suggests that they evolved from different ancestral species.

The assignment of conidiomata found on the pseudothecia of Paraleptosphaeria polylepidis to a new phylogenetic lineage of the Dictyosporiaceae was unexpected as we earlier hypothesized having encountered the asexual state of $\mathrm{Pa}$. polylepidis. The sequences obtained from the fungus formed
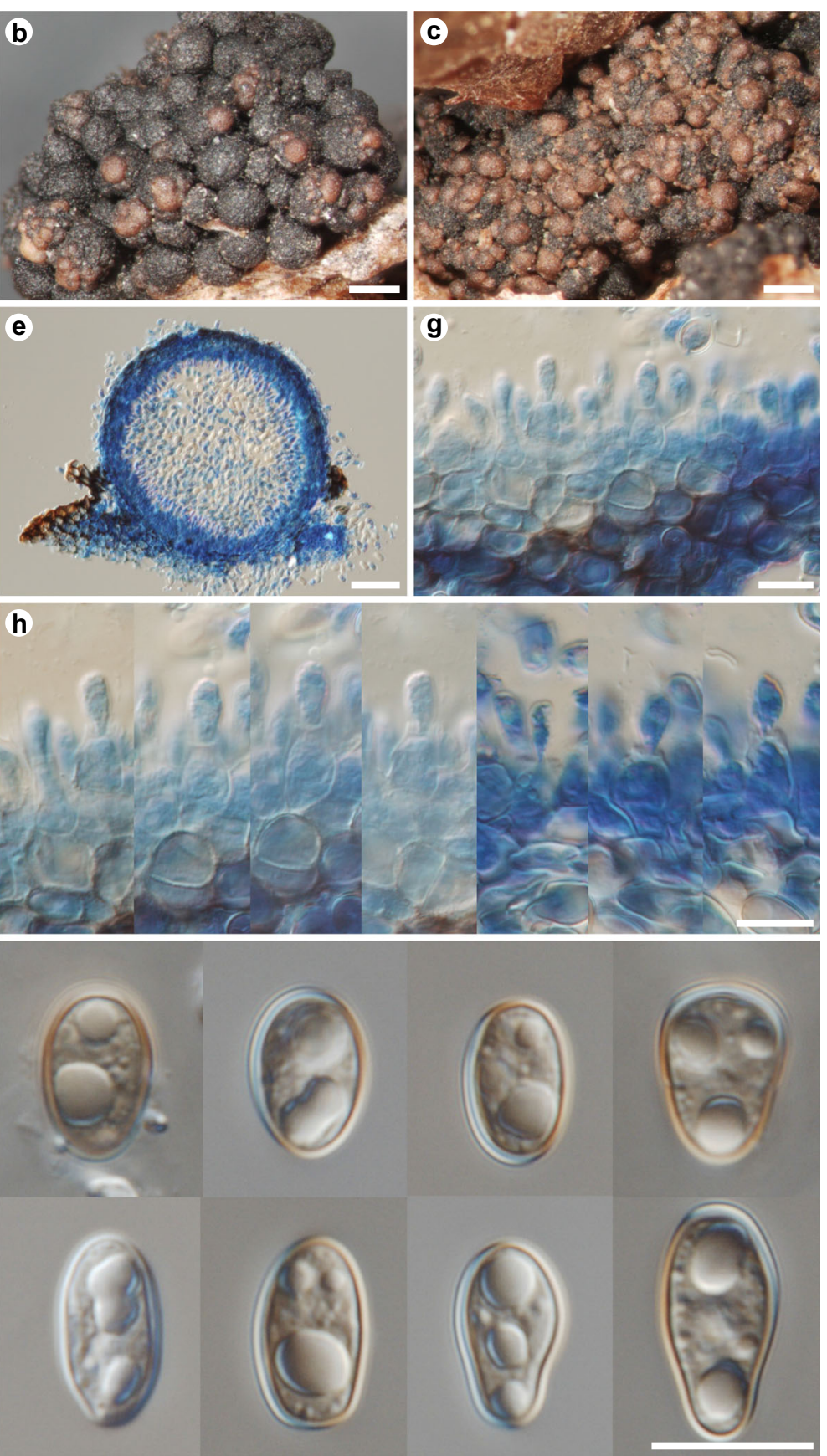

cells (hyaline areas) and conidial masses (brown areas). g Section through paraplectenchymatous peridium showing conidiogenous cells mounted in LPCB. $\mathbf{h}$ Conidiogenous cells and young conidia mounted in LPCB. i Conidia. Scale bars: a $1000 \mu \mathrm{m}, \mathbf{b}-\mathbf{c} 500 \mu \mathrm{m}, \mathbf{d}-\mathbf{f}$ $50 \mu \mathrm{m}, \mathbf{g}-\mathbf{i} 10 \mu \mathrm{m}$

a strongly supported sister clade to members of the genus Pseudocoleophoma but could not be classified in Pseudocoleophoma on the basis of different morphological characteristics. The genus Pseudocoleophoma has been described for two species, Ps. calamagrostidis (generic type) and Ps. polygonicola, that produced sexual states on the natural substrates and asexual states in cultures (Tanaka et al. 
2015). Two more species have been described later, $P S$. typhicola forming only asexual state on the natural substrate (Hyde et al. 2016) and Ps. bauhiniae producing both asexual and sexual states on the natural substrate (Jayasiri et al. 2019). While the fungus found on the pseudothecia of Pa. polylepidis lacks a sexual state and forms uniloculate to multi-loculate pycnidia and pale brown, broadly ellipsoidal conidia, the species of Pseudocoleophoma usually produce a sexual state and pycnidia of the asexual state are uniloculate and the cylindrical conidia are hyaline. It also differs ecologically by parasitism on another fungus, while all Pseudocoleophoma species are saprobic on dead plant materials. Though we did not check mycelial interactions in culture experiments, the fungus forms pycnidia erumpent through the outermost layer of host peridium and, therefore, is likely mycoparasitic (at least necrotrophic as defined by Sun et al. 2019). Furthermore, the molecular phylogenetic analyses indicated genetic distances between this fungus and Pseudocoleophoma comparable to distances between other Dictyosporiaceae clades, assigned to distinct genera (Boonmee et al. 2016). No morphologicaly similar coelomycete genus was found in Sutton (1980) and in the recent literature; therefore, a new genus and species names, Sajamaea and S. mycophila, are introduced for this fungus. The family Dictyosporiaceae contains mostly asexual species, while sexual species are very rare, being represented only by Dictyosporium meiosporum, D. sexualis, Gregarithecium curvisporum, Pseudocoleophoma calamagrostidis, P. polygonicola, and P. bauhiniae (Tanaka et al. 2015; Boonmee et al. 2016; Jayasiri et al. 2019). The asexual species are mostly hyphomycetous, often producing characteristic cheirosporous conidia (Tanaka et al. 2015; Boonmee et al. 2016; IturrietaGonzález et al. 2018; Yang et al. 2018), but Sajamaea and Pseudocoleophoma have coelomycetous asexual states, which supports their close phylogenetic relationship.

The parasitism of Sajamaea mycophila suggests that this species may be potentially used as a biopesticide that could prevent the development of Paraleptosphaeria polylepidis and consequently protect Polylepis tarapacana woodlands.

Additional emphases are thus required to re-collect S. mycophila and aim at culturing it in order to unravel its mycoparasitic and biopesticidal potentials.

Acknowledgments We appreciate the support of Cecilia López and the staff of the Sajama National Park for their collaboration in field work. We are greatly indebted to all staff of the Herbario Nacional de Bolivia, Instituto de Ecología, Universidad Mayor de San Andrés, La Paz, for their generous long-term cooperation.

Funding information The study was funded by the International Foundation for Science (IFS). Research on the mycoparasitic fungus was financially supported by the National Science Centre $(\mathrm{NCN})$ in Poland (DEC-2013/11/D/NZ8/03274). MP, PRF and AF received additional support under statutory funds from the W. Szafer Institute of Botany, Polish Academy of Sciences, Kraków, Poland.
Open Access This article is distributed under the terms of the Creative Commons Attribution 4.0 International License (http:// creativecommons.org/licenses/by/4.0/), which permits unrestricted use, distribution, and reproduction in any medium, provided you give appropriate credit to the original author(s) and the source, provide a link to the Creative Commons license, and indicate if changes were made.

\section{References}

Altschul SF, Madden TL, Schäffer AA, Zhang J, Zhang Z, Miller W, Lipman DJ (1997) Gapped BLAST and PSI-BLAST: a new generation of protein database search programs. Nucleic Acids Res 25: 3389-3402

Alves JL, Woudenberg JH, Duarte LL, Crous PW, Barreto RW (2013) Reappraisal of the genus Alternariaster (Dothideomycetes). Persoonia 31:77-85

Ariyawansa HA, Phukhamsakda C, Thambugala KM, Bulgakov TS, Wanasinghe DN, Perera RH, Mapook A, Camporesi E, Kang JC, Jones GEB, Bahkali AH, Jayasiri SC, Hyde KD, Liu ZY, Bhat JD (2015) Revision and phylogeny of Leptosphaeriaceae. Fungal Divers 74:19-51

Aveskamp MM, Verkley GJ, de Gruyter J, Murace MA, Perello A, Woudenberg JH, Groenewald JZ, Crous PW (2009) DNA phylogeny reveals polyphyly of Phoma section Peyronellaea and multiple taxonomic novelties. Mycologia 101:363-382

Aveskamp MM, de Gruyter J, Woudenberg JH, Verkley GJ, Crous PW (2010) Highlights of the Didymellaceae: A polyphasic approach to characterise Phoma and related pleosporalean genera. Stud Mycol 65:1-60

Azócar A, Rada F, García-Núñez C (2007) Functional characteristics of the arborescent genus Polylepis along a latitudinal gradient in the high Andes. Interciencia 32:663-666

Boonmee S, D'souza MJ, Luo Z, Pinruan U, Tanaka K, Su H, Bhat DJ, McKenzie EHC, Jones EBG, Taylor JE, Phillips AJL, Hirayama K, Eungwanichayapant PD, Hyde KD (2016) Dictyosporiaceae fam. nov. Fungal Divers 80:457-482

Cai L, Guo XY, Hyde KD (2008) Morphological and molecular characterisation of a new anamorphic genus Cheirosporium, from freshwater in China. Persoonia 20:53-58

Camara MP, Palm ME, van Berkum P, O'Neill NR (2002) Molecular phylogeny of Leptosphaeria and Phaeosphaeria. Mycologia 94: 630-640

Chen Q, Jiang JR, Zhang GZ, Cai L, Crous PW (2015) Resolving the Phoma enigma. Stud Mycol 82:137-217

Coca-Morante M (2012) Assessment of Lepthosphaeria [sic!] polylepidis decline in Polylepis tarapacana Phil. trees in District 3 of the Sajama National Park, Bolivia. In: Oteng-Amoako AA (ed) New advances and contributions to forestry research. InTech, Rijeka, pp $147-158$

Crous PW, Schoch CL, Hyde KD, Wood AR, Gueidan C, de Hoog GS, Groenewald JZ (2009) Phylogenetic lineages in the Capnodiales. Stud Mycol 64:17-47

Crous PW, Wingfield MJ, Richardson DM, Le Roux JJ, Strasberg D, Edwards J, Roets F, Hubka V, Taylor PWJ, Heykoop M, Martín MP, Moreno G, Sutton DA, Wiederhold NP, Barnes CW, Carlavilla JR, Gené J, Giraldo A, Guarnaccia V, Guarro J, Hernández-Restrepo M, Kolařík M, Manjón JL, Pascoe IG, Popov ES, Sandoval-Denis M, Woudenberg JHC, Acharya K, Alexandrova AV, Alvarado P, Barbosa RN, Baseia IG, Blanchette RA, Boekhout T, Burgess TI, Cano-Lira JF, Čmoková A, Dimitrov RA, Dyakov MY, Dueñas M, Dutta AK, Esteve Raventós F, Fedosova AG, Fournier J, Gamboa P, Gouliamova DE, Grebenc T, 
Groenewald M, Hanse B, Hardy GESJ, Held BW, Jurjević Ž, Kaewgrajang T, Latha KPD, Lombard L, Luangsa-ard JJ, Lysková P, Mallátová N, Manimohan P, Miller AN, Mirabolfathy M, Morozova OV, Obodai M, Oliveira NT, Ordóñez ME, Otto EC, Paloi S, Peterson SW, Phosri C, Roux J, Salazar WA, Sánchez A, Sarria GA, Shin HD, Silva BDB, Silva GA, Smith MT, Souza-Motta CM, Stchigel AM, Stoilova-Disheva MM, Sulzbacher MA, Telleria MT, Toapanta C, Traba JM, Valenzuela-Lopez N, Watling R, Groenewald JZ (2016) Fungal Planet description sheets: 400-468. Persoonia 36:316-458

Cuyckens GAE, Christie DA, Domic AI, Malizia LR, Renison D (2016) Climate change and the distribution and conservation of the world's highest elevation woodlands in the South American Altiplano. Glob Planet Change 137:79-87

Dayarathne MC, Phookamsak R, Ariyawansa HA, Jones EBG, Camporesi E, Hyde KD (2015) Phylogenetic and morphological appraisal of Leptosphaeria italica sp. nov. (Leptosphaeriaceae, Pleosporales) from Italy. Mycosphere 6:634-642

de Gruyter J, Aveskamp MM, Woudenberg JH, Verkley GJ, Groenewald JZ, Crous PW (2009) Molecular phylogeny of Phoma and allied anamorph genera: towards a reclassification of the Phoma complex. Mycol Res 113:508-519

de Gruyter J, Woudenberg JHC, Aveskamp MM, Verkley GJM, Groenewald JZ, Crous PW (2010) Systematic reappraisal of species in Phoma section Paraphoma, Pyrenochaeta and Pleurophoma. Mycologia 102:1066-1081

de Gruyter J, Woudenberg JH, Aveskamp MM, Verkley GJ, Groenewald JZ, Crous PW (2013) Redisposition of phoma-like anamorphs in Pleosporales. Stud Mycol 75:1-36

Domic AI, Camilo GR, Capriles JM (2014) Small-scale farming and grazing reduce regeneration of Polylepis tomentella (Rosaceae) in the Semiarid Andes of Bolivia. Biotropica 46(1):106-113

Fjeldså J, Kessler M (1996) Conserving the biological diversity of Polylepis woodlands of the highland of Peru and Bolivia. NORDECO, Copenhagen

Flakus A, Etayo J, Pérez-Ortega S, Kukwa M, Palice Z, RodriguezFlakus P (2019) A new genus Zhurbenkoa and a novel nutritional mode revealed in the family Malmideaceae (Lecanoromycetes, Ascomycota). Mycologia 111:593-611

Gardes M, Bruns TD (1993) ITS primers with enhanced specificity for basidiomycetes - application to the identification of mycorrhizae and rusts. Mol Ecol 2:113-118

Gargas A, Taylor JW (1992) Polymerase chain reaction (PCR) primers for amplifying and sequencing nuclear 18S rDNA from lichenized fungi. Mycologia 84:589-592

González JA, Gallardo MG, Boero C, Liberman-Cruz M, Prado FE (2007) Altitudinal and seasonal variation of protective and photosynthetic pigments in leaves of the world's highest elevation trees Polylepis tarapacana (Rosaceae). Acta Oecol 32:36-41

Huelsenbeck JP, Ronquist F (2001) MRBAYES: Bayesian inference of phylogeny. Bioinformatics 17:754-755

Hurtado R, Palabral-Aguilera AN, Domic AI, Gómez MI, Liberman M (2018) Estudios etnobotánicos y florísticos de los bosques amenazados de Polylepis incarum y Polylepis pacensis (Rosaceae) en Bolivia. Bonplandia 27:113-126

Hyde KD, Hongsanan S, Jeewon R, Bhat DJ, McKenzie EHC, Jones EBG, Phookamsak R, Ariyawansa HA, Boonmee S, Zhao Q, Abdel-Aziz FA, Abdel-Wahab MA, Banmai S, Chomnunti P, Cui BK, Daranagama DA, Das K, Dayarathne MC, de Silva NI, Dissanayake AJ, Doilom M, Ekanayaka AH, Gibertoni TB, GóesNeto A, Huang SK, Jayasiri SC, Jayawardena RS, Konta S, Lee HB, Li WJ, Lin CG, Liu JK, Lu YZ, Luo ZL, Manawasinghe IS, Manimohan P, Mapook A, Niskanen T, Norphanphoun C, Papizadeh M, Perera RH, Phukhamsakda C, Richter C, de A. Santiago ALCM, Drechsler-Santos ER, Senanayake IC, Tanaka K, TMDS T, Thambugala KM, Tian Q, Tibpromma S, Thongbai B,
Vizzini A, Wanasinghe DN, Wijayawardene NN, Wu HX, Yang J, Zeng XY, Zhang H, Zhang JF, Bulgakov TS, Camporesi E, Bahkali AH, Amoozegar MA, Araujo-Neta LS, Ammirati JF, Baghela A, Bhatt RP, Bojantchev D, Buyck B, da Silva GA, de Lima CLF, de Oliveira RJV, de Souza CAF, Dai YC, Dima B, Duong TT, Ercole E, Mafalda-Freire F, Ghosh A, Hashimoto A, Kamolhan S, Kang JC, Karunarathna SC, Kirk PM, Kytöuori I, Lantieri A, Liimatainen K, Liu ZY, Liu XZ, Lücking R, Medardi G, Mortimer PE, TTT N, Promputtha I, KNA R, Reck MA, Lumyong S, SAS F, Stadler M, Soudi MR, Su HY, Takahashi T, Tangthirasunun N, Uniyal P, Wang Y, Wen TC, Xu JC, Zhang ZK, Zhao YC, Zhou JL, Zhu L (2016) Fungal diversity notes 367-490: taxonomic and phylogenetic contributions to fungal taxa. Fungal Divers 80:1-270

Iturrieta-González I, Gené J, Guarro J, Castañeda-Ruiz RF, García D (2018) Neodendryphiella, a novel genus of the Dictyosporiaceae (Pleosporales). MycoKeys 37:19-38

Jayasiri SC, Hyde KD, Jones EBG, McKenzie EHC, Jeewon R, Phillips AJL, Bhat DJ, Wanasinghe DN, Liu JK, Lu YZ, Kang JC, Xu J, Karunarathna SC (2019) Diversity, morphology and molecular phylogeny of Dothideomycetes on decaying wild seed pods and fruits. Mycosphere 10:1-186

Jones EBG, Klaysuban A, Pang KL (2008) Ribosomal DNA phylogeny of marine anamorphic fungi: Cumulospora varia, Dendryphiella species and Orbimyces spectabilis. The Raffles B Zool, Suppl No. 19:11-18

Jordan E (1980) Das durch Wärmemangel und Trockenheit begrenzte Auftreten von Polylepis am Sajama Boliviens mit dem höchsten Polylepis-Gebüschvorkommen der Erde. Deutscher Geographentag 42:303-305

Katoh K, Kuma K, Toh H, Miyata T (2005) MAFFT version 5: improvement in accuracy of multiple sequence alignment. Nucleic Acids Res 33:511-518

Kessler M (1995) The genus Polylepis (Rosaceae) in Bolivia. Candollea 50:131-171

Kessler M (2006) Bosques de Polylepis. In: Moraes M, Øllgaard B, Kvist LP, Borchsenius F, Balslev H (eds) Botánica Económica de los Andes Centrales. Universidad Mayor de San Andrés, La Paz, Bolivia, pp 110-120

Kirschner R, Pang KL, Jones EBG (2013) Two cheirosporous hyphomycetes reassessed based on morphological and molecular examination. Mycol Prog 12:29-36

Lanfear R, Frandsen PB, Wright AM, Senfeld T, Calcott B (2016) PartitionFinder 2: new methods for selecting partitioned models of evolution for molecular and morphological phylogenetic analyses. Mol Biol Evol 34:772-773

Li WL, Luo ZL, Liu JK, Bhat DJ, Bao DF, Su HY, Hyde KD (2017) Lignicolous freshwater fungi from China I: Aquadictyospora lignicola gen. et sp. nov. and new record of Pseudodictyosporium wauense from northwestern Yunnan Province. Mycosphere 8:15871597

Liu JK, Hyde KD, Jones EBG, Ariyawansa HA, Bhat DJ, Boonmee S, Maharachchikumbura SSN, McKenzie EHC, Phookamsak R, Phukhamsakda C, Shenoy BD, Abdel-Wahab MA, Buyck B, Chen J, Chethana KWT, Singtripop C, Dai DQ, Dai YC, Daranagama DA, Dissanayake AJ, Doilom M, D'souza MJ, Fan XL, Goonasekara ID, Hirayama K, Hongsanan S, Jayasiri SC, Jayawardena RS, Karunarathna SC, Li WJ, Mapook A, Norphanphoun C, Pang KL, Perera RH, Peršoh D, Pinruan U, Senanayake IC, Somrithipol S, Suetrong S, Tanaka K, Thambugala KM, Tian Q, Tibpromma S, Udayanga D, Wijayawardene NN, Wanasinghe D, Wisitrassameewong K, Zeng XY, Abdel-Aziz FA, Adamčík S, Bahkali AH, Boonyuen N, Bulgakov T, Callac P, Chomnunti P, Greiner K, Hashimoto A, Hofstetter V, Kang JC, Lewis D, Li XH, Liu XZ, Liu ZY, Matsumura M, Mortimer PE, Rambold G, Randrianjohany E, Sato G, Sri-Indrasutdhi V, Tian CM, Verbeken A, von Brackel W, Wang 
Y, Wen TC, Xu JC, Yan JY, Zhao RL, Camporesi E (2015) Fungal diversity notes 1-110: taxonomic and phylogenetic contributions to fungal species. Fungal Divers 72:1-197

Macia MJ, Palm ME, Martin MP (2005) A new species of Leptosphaeria (Ascomycotina, Pleosporales) on Rosaceae from Bolivia. Mycotaxon 93:401-406

Mendes-Pereira E, Balesdent MH, Brun H, Rouxel T (2003) Molecular phylogeny of the Leptosphaeria maculans-Leptosphaeria biglobosa species complex. Mycol Res 107:1287-1304

Miller MA, Pfeiffer W, Schwartz T (2010) Creating the CIPRES Science Gateway for inference of large phylogenetic trees. In: Proceedings of the Gateway Computing Environments Workshop (GCE). 14 Nov. 2010. New Orleans Convention Center, New Orleans, LA, pp 1-8

Ministerio de Medio Ambiente y Agua (MMAyA) (2012) LIBRO ROJO de la Flora amenazada de Bolivia, vol I. Zona Andina, La Paz

Navarro G, Molina JA, de la Barra N (2005) Classification of the highAndean Polylepis forests in Bolivia. Plant Ecol 176:113-130

Penn O, Privman E, Ashkenazy H, Landan G, Graur D, Pupko T (2010) GUIDANCE: a web server for assessing alignment confidence scores. Nucleic Acids Res 38:23-28

Potter D, Eriksson T, Evans RC, Oh S, Smedmark JEE, Morgan DR, Kerr M, Robertson KR, Arsenault M, Dickinson TA, Campbell CS (2007) Phylogeny and classification of Rosaceae. Plant Syst Evol 266:5-43

Rada F, García-Núñez C, Boero C, Gallardo M, Hilal M, González J, Prado F, Liberman-Cruz M, Azócar A (2001) Low temperature resistance in Polylepis tarapacana, a tree growing at the highest altitudes in the world. Plant Cell Environ 24:377-381

Rehner S, Buckley E (2005) A Beauveria phylogeny inferred from nuclear ITS and EF1-alpha sequences: evidence for cryptic diversification and links to Cordyceps teleomorphs. Mycologia 97:84-98

Rehner SA, Samuels GJ (1994) Taxonomy and phylogeny of Gliocladium analysed from nuclear large subunit ribosomal DNA sequences. Mycol Res 98:625-634

Rodriguez-Flakus P, Printzen C (2014) Palicella, a new genus of lichenized fungi and its phylogenetic position within Lecanoraceae. Lichenologist 46:535-552

Ronquist F, Huelsenbeck JP (2003) MrBayes 3: Bayesian phylogenetic inference under mixed models. Bioinformatics 19:1572-1574

Schoch CL, Crous PW, Groenewald JZ, Boehm EW, Burgess TI, de Gruyter J, de Hoog GS, Dixon LJ, Grube M, Gueidan C, Harada Y, Hatakeyama S, Hirayama K, Hosoya T, Huhndorf SM, Hyde KD, Jones EB, Kohlmeyer J, Kruys A, Li YM, Lücking R, Lumbsch HT, Marvanová L, Mbatchou JS, McVay AH, Miller AN, Mugambi GK, Muggia L, Nelsen MP, Nelson P, Owensby CA, Phillips AJ, Phongpaichit S, Pointing SB, Pujade-Renaud V, Raja HA, Plata ER, Robbertse B, Ruibal C, Sakayaroj J, Sano T, Selbmann L, Shearer CA, Shirouzu T, Slippers B, Suetrong S, Tanaka K, Volkmann-Kohlmeyer B, Wingfield MJ, Wood AR, Woudenberg JH, Yonezawa H, Zhang Y, Spatafora JW (2009) A class-wide phylogenetic assessment of Dothideomycetes. Stud Mycol 64:1-15

Simpson BB (1979) A revision of the genus Polylepis (Rosaceae: Sanguisorbeae) Smithsonian Contributions to Botany, vol 43. Smithsonian Institution Press, Washington

Stamatakis A (2014) RAxML Version 8: A tool for phylogenetic analysis and post-analysis of large phylogenies. Bioinformatics 30(9):13121313

Sun JZ, Liu XZ, McKenzie EHC, Jeewon R, Liu JKJ, Zhang XL, Zhao Q, Hyde KD (2019) Fungicolous fungi: terminology, diversity, distribution, evolution, and species checklist. Fungal Divers 95:337-430

Sutton BC (1980) The Coelomycetes, Fungi Imperfecti with acervuli, pycnidia and stromata. Commonwealth Mycological Institute, Kew
Tanaka K, Hirayama K, Yonezawa H, Sato G, Toriyabe A, Kudo H, Hashimoto A, Matsumura M, Harada Y, Kurihara Y, Shirouzu T, Hosoya T (2015) Revision of the Massarineae (Pleosporales, Dothideomycetes). Stud Mycol 82:75-136

Tibpromma S, Hyde KD, Jeewon R, Maharachchikumbura SSN, Liu JK, Bhat DJ, Jones EBG, McKenzie EHC, Camporesi E, Bulgakov TS, Doilom M, Santiago ALCMA, Das K, Manimohan P, Gibertoni TB, Lim YW, Ekanayaka AH, Thongbai B, Lee HB, Yang JB, Kirk PM, Sysouphanthong P, Singh SK, Boonmee S, Dong W, Raj KNA, Latha KPD, Phookamsak R, Phukhamsakda C, Konta S, Jayasiri SC, Norphanphoun C, Tennakoon DS, Li J, Dayarathne MC, Perera RH, Xiao Y, Wanasinghe DN, Senanayake IC, Goonasekara ID, de Silva NI, Mapook A, Jayawardena RS, Dissanayake AJ, Manawasinghe IS, Chethana KWT, Luo ZL, Hapuarachchi KK, Baghela A, Soares AM, Vizzini A, MeirasOttoni A, Mešić A, Dutta AK, de Souza CAF, Richter C, Lin CG, Chakrabarty D, Daranagama DA, Lima DX, Chakraborty D, Ercole E, Wu F, Simonini G, Vasquez G, da Silva GA, Plautz HL Jr, Ariyawansa HA, Lee H, Kušan I, Song J, Sun J, Karmakar J, Hu $\mathrm{K}$, Semwal KC, Thambugala KM, Voigt K, Acharya K, Rajeshkumar KC, Ryvarden L, Jadan M, Hosen MI, Mikšík M, Samarakoon MC, Wijayawardene NN, Kim NK, Matočec N, Singh PN, Tian Q, Bhatt RP, de Oliveira RJV, Tulloss RE, Aamir S, Kaewchai S, Marathe SD, Khan S, Hongsanan S, Adhikari S, Mehmood T, Bandyopadhyay TK, Svetasheva TY, Nguyen TTT, Antonín V, Li WJ, Wang Y, Indoliya Y, Tkalčec Z, Elgorban AM, Bahkali AH, Tang AMC, Su HY, Zhang H, Promputtha I, Luangsaard J, Xu J, Yan J, Ji-Chuan K, Stadler M, Mortimer PE, Chomnunti P, Zhao Q, Phillips AJL, Nontachaiyapoom S, Wen TC, Karunarathna SC (2017) Fungal diversity notes 491-602: taxonomic and phylogenetic contributions to fungal taxa. Fungal Divers 83: $1-261$

Tsui CKM, Berbee ML, Jeewon R, Hyde KD (2006) Molecular phylogeny of Dictyosporium and allied genera inferred from ribosomal DNA. Fungal Divers 21:157-166

Verkley GJ, Dukik K, Renfurm R, Göker M, Stielow JB (2014) Novel genera and species of coniothyrium-like fungi in Montagnulaceae (Ascomycota). Persoonia 32:25-51

Vilgalys R, Hester M (1990) Rapid genetic identification and mapping of enzymatically amplified ribosomal DNA from several Cryptococcus species. J Bacteriol 172:4238-4246

Wanasinghe DN, Camporesi E, Hu DM (2016) Neoleptosphaeria jonesii sp. nov., a novel saprobic sexual species, in Leptosphaeriaceae. Mycosphere 7:1368-1377

Wang RX, Luo ZL, Hyde KD, Bhat DJ, Su XJ, Su HY (2016) New species and records of Dictyocheirospora from submerged wood in north-western Yunnan, China. Mycosphere 7:1357-1367

White TJ, Bruns T, Lee S, Taylor J (1990) Amplification and direct sequencing of fungal ribosomal RNA genes for phylogenetics. In: Innis MA, Gelfand DH, Sninsky JJ, White TJ (eds) PCR Protocols: a guide to methods and applications. Academic Press, San Diego, pp 315-322

Woudenberg JH, Groenewald JZ, Binder M, Crous PW (2013) Alternaria redefined. Stud Mycol 75:171-212

Yang J, Liu JK, Hyde KD, Jones EBG, Liu ZY (2018) New species in Dictyosporium, new combinations in Dictyocheirospora and an updated backbone tree for Dictyosporiaceae. MycoKeys 36:83-105

Zhang Y, Crous PW, Schoch CL, Hyde KD (2012) Pleosporales. Fungal Divers 53:1-221

Publisher's note Springer Nature remains neutral with regard to jurisdictional claims in published maps and institutional affiliations. 